\title{
The molecular pathogenesis of superoxide dismutase 1-linked ALS is promoted by low oxygen tension
}

\author{
Isil Keskin ${ }^{1}$ - Elin Forsgren ${ }^{2} \cdot$ Manuela Lehmann $^{2} \cdot$ Peter M. Andersen ${ }^{2} \cdot$ Thomas Brännström $^{1} \cdot$ Dale J. Lange ${ }^{3}$. \\ Matthis Synofzik ${ }^{4,5}$. Ulrika Nordström ${ }^{2} \cdot$ Per Zetterström $^{6} \cdot$ Stefan L. Marklund ${ }^{6}$. Jonathan D. Gilthorpe ${ }^{2} \mathbb{C}$
}

Received: 12 October 2018 / Revised: 25 February 2019 / Accepted: 1 March 2019 / Published online: 12 March 2019

(c) The Author(s) 2019

\begin{abstract}
Mutations in superoxide dismutase 1 (SODI) cause amyotrophic lateral sclerosis (ALS). Disease pathogenesis is linked to destabilization, disorder and aggregation of the SOD1 protein. However, the non-genetic factors that promote disorder and the subsequent aggregation of SOD1 have not been studied. Mainly located to the reducing cytosol, mature SOD1 contains an oxidized disulfide bond that is important for its stability. Since $\mathrm{O}_{2}$ is required for formation of the bond, we reasoned that low $\mathrm{O}_{2}$ tension might be a risk factor for the pathological changes associated with ALS development. By combining biochemical approaches in an extensive range of genetically distinct patient-derived cell lines, we show that the disulfide bond is an Achilles heel of the SOD1 protein. Culture of patient-derived fibroblasts, astrocytes, and induced pluripotent stem cell-derived mixed motor neuron and astrocyte cultures (MNACs) under low $\mathrm{O}_{2}$ tensions caused reductive bond cleavage and increases in disordered SOD1. The effects were greatest in cells derived from patients carrying ALS-linked mutations in SOD1. However, significant increases also occurred in wild-type SOD1 in cultures derived from non-disease controls, and patients carrying mutations in other common ALS-linked genes. Compared to fibroblasts, MNACs showed far greater increases in SOD1 disorder and even aggregation of mutant SOD1s, in line with the vulnerability of the motor system to SOD1-mediated neurotoxicity. Our results show for the first time that $\mathrm{O}_{2}$ tension is a principal determinant of SOD1 stability in human patient-derived cells. Furthermore, we provide a mechanism by which non-genetic risk factors for ALS, such as aging and other conditions causing reduced vascular perfusion, could promote disease initiation and progression.
\end{abstract}

Keywords Amyotrophic lateral sclerosis (ALS) - Superoxide dismutase 1 (SOD1) · Disulfide bond · Oxygen tension · Protein disorder $\cdot$ Protein aggregation $\cdot$ Patient-derived cells

\section{Introduction}

Electronic supplementary material The online version of this article (https://doi.org/10.1007/s00401-019-01986-1) contains supplementary material, which is available to authorized users.

Stefan L. Marklund

stefan.marklund@umu.se

Jonathan D. Gilthorpe

jonathan.gilthorpe@umu.se

1 Department of Medical Biosciences, Pathology, Umeå University, 90185 Umeå, Sweden

2 Department of Pharmacology and Clinical Neuroscience, Umeå University, 90187 Umeå, Sweden

3 Department of Neurology, Hospital for Special Surgery and Weill Cornell Medical Center, New York, NY 10021, USA
Amyotrophic lateral sclerosis (ALS) is characterized by adult-onset progressive degeneration of upper and lower motor neurons $(\mathrm{MN})$. Usually, the disease begins focally and

4 Department of Neurodegenerative Diseases, Hertie Institute for Clinical Brain Research, University of Tübingen, Tübingen, Germany

5 German Research Center for Neurodegenerative Diseases (DZNE), 72076 Tübingen, Germany

6 Department of Medical Biosciences, Clinical Chemistry, Umeå University, 90185 Umeå, Sweden 
then spreads contiguously, resulting in progressive paralysis and death from respiratory failure [20]. Mutations in superoxide dismutase 1 (SOD1) cause ALS [65], and are found in $1-9 \%$ of patients [3].

Human SOD1 is composed of two equal 153 amino acidlong subunits, each of which contains one copper and one zinc ion and a stabilizing C57-C146 disulfide bond required for dimerization. Of over 200 mutations identified in ALS patients, about $90 \%$ are missense and encode SOD1 variants that are destabilized to differing degrees. However, the proportion of disordered to natively folded protein varies widely between different mutations in patient cells $[6,47,50,51$, $68,71]$. The other mutations encode mutants with structural alterations (insertions, fusions, internal deletions and C-terminal truncations). Most of the truncation mutations disrupt both the $\beta$-barrel core and the stabilizing intrasubunit C57-C146 disulfide bond of the protein. These mutants are intrinsically disordered, since they cannot fold correctly, and are rapidly degraded $[13,45,50,51,68]$. Based on these observations, it is likely that any common ALS-causing SOD1 species is disordered, lacks the C57-C146 disulfide bond, and is present at very low levels.

Although the involvement of wild-type SOD1 (SOD $1{ }^{\mathrm{WT}}$ ) in ALS is contentious [9, 17, 27], there is an increasing body of evidence that has identified the presence of disordered and aggregated SOD1 in motor areas of the CNS in ALS patients that lack SOD1 mutations [15, 31, 32, 33, $39,56,60,62]$. Co-culture of motor neurons with primary astrocytes derived from sporadic ALS patients supports the involvement of SOD $1^{\mathrm{WT}}$ in disease pathogenesis [41]. In addition, transgenic (Tg) mice that express human SOD ${ }^{\text {WT }}$ to a sufficient level develop both SOD1 aggregation and a fatal ALS-like disease [40]. These findings suggest that disordered SOD $1{ }^{\mathrm{WT}}$ could be more widely involved in ALS pathology than previously recognized.

SOD1 is an ancient enzyme and was secreted to the oxidizing extracellular space in early unicellular organisms, as well as in current $\alpha$-bacteria $[14,58]$. However, human SOD1 is localized primarily to the cytosol, which is strongly reducing. Hence, the C57-C146 bond could be an evolutionrelated Achilles heel of eukaryotic SOD1 due to vulnerability to reductive cleavage. The absence of the disulfide bond promotes disorder of the protein and its aggregation in vitro [21, 22, 35, 51, 53]. Moreover, soluble disordered and aggregated SOD1 in the CNS of human SOD1 Tg mice lacks the bond $[10,48,77,78]$. Hence, C57-C146 appears to be a critical determinant of the role of SOD1 in ALS. However, factors that impact upon the formation and maintenance of the bond are not understood.

Age is the principal non-hereditary risk factor for ALS. It is associated with reduced perfusion in the CNS owing to vascular wall degeneration and neurovascular unit dysfunction [43]. Other suggested risk factors include smoking [37],
CNS trauma, particularly to the motor cortex [66], embolisations of arteriovenous malformations [24, 54, 66, 72], transient ischemic attack, and stroke [72]. Strenuous physical activity has also been suggested to increase the risk for ALS [23], although this is contentious [38]. The underlying mechanisms are not understood, but a unifying characteristic could be reduced vascular perfusion leading to transient or chronic local CNS hypoxia.

The major pathway for C57-C146 disulfide formation is dependent on $\mathrm{O}_{2}$ and catalyzed by a copper chaperone for superoxide dismutase (CCS) [26, 30, 36]. Hence, we hypothesized that lowered $\mathrm{O}_{2}$ tension may impact negatively on SOD1 stability. To test this, we took advantage of an extensive collection of genetically defined cell lines derived from SOD1 ALS and non-SOD1 ALS patients, as well as from non-disease controls. As in vitro models of ALS, we used dermal fibroblasts, primary spinal cord-derived astrocytes, and induced pluripotent stem cell-(iPSC) derived mixed motor neuron and astrocyte cultures (MNACs). Analysis of lines carrying biochemically and structurally distinct SOD1 variants has enabled us to show, for the first time, that low $\mathrm{O}_{2}$ tension markedly increases the proportion of disordered, disulfide bond-reduced and aggregated SOD1 in a time and concentration-dependent manner and may be a risk factor for ALS development.

\section{Materials and methods}

\section{Human materials}

Samples from patients and non-disease controls (Supplementary Table 1), including blood samples for genotyping and skin biopsies for fibroblast culture, were collected with approval of the Regional Ethical Review Board in Umeå and in accordance with the principles of the Declaration of Helsinki (WMA, 1964), following written informed consent.

\section{Reagents and chemicals}

Reagents and chemicals were obtained from Sigma or Thermo Fisher Scientific unless stated otherwise.

\section{SOD1, FUS, TBK1 and C9orf72 genotyping}

ALS patients were diagnosed according to EFNS guidelines [4]. Blood was screened to identify SOD1, C9orf72, TBK1 or FUS mutation carriers. Genotyping for $S O D 1, C 9$ orf 72 [51] and TBK1 [34] were performed as described. For FUS, only exons 2-6 and 11-15 were analyzed. All individuals tested negative for mutations in a panel of other ALS-linked genes (details available on request). 


\section{Derivation of human fibroblasts}

Fibroblasts were generated from a $3 \mathrm{~mm}$ punch skin biopsy (upper arm) from 10 ALS patients with mutations in SOD1 (A4V, H46R, E78_R79insSI, N86S, D90A, G93A, L117V, D125Tfs*24 or G127Gfs*7 (G127X; two patients), one ALS patient with a mutation in FUS (Q23L), four ALS patients with mutations in TBK1 (A417X, M598V, I450Kfs*14 or p.690-713del), one ALS and one FTD patient with massive intronic GGGGCC repeat-expansions in $C 9$ orf 72 , and four non-disease control individuals (Supplementary Table 1). All patients were heterozygous for their corresponding mutations except for the homozygous $S O D 1^{D 90 A}$ patient. All non-disease control subjects were relatives of ALS patients and tested negatively $(\mathrm{wt} / \mathrm{wt}$ ) for a panel of ALS-associated genes including SOD1, C9orf72, TBK1, FUS and UBQLN2 (details available on request). The establishment of lines followed standard procedures [51].

\section{Generation and maintenance of iPSCs}

Fibroblast lines were reprogrammed with either the mRNA Reprogramming Kit (Stemgent, Cambridge, MA, USA) [74] using a commercial service (Cellectis AB, Gothenburg, Sweden), or using episomal vectors [59] (Supplementary Table 1). After seeding at a density of 40,000 cells/ $\mathrm{cm}^{2}$, iPSCs were cultured using the DEF-CS culture system (Takara Bio Europe, Gothenburg, Sweden). Media changes were performed every $24 \mathrm{~h}$ and cells were passaged using TrypLE every 3-4 days after reaching a density of $1.5-2 \times 10^{5}$ cells $/ \mathrm{cm}^{2}$.

\section{Generation of iPSC-MNACs}

To differentiate MNACs, iPSCs at $90 \%$ confluence were switched into N2/B27 media, consisting of 1:1 DMEM/ F12:Neurobasal, 1x Non Essential Amino Acids (NEAA; Millipore, Bedford, MA, USA), 2 mM L-glutamine, 1\% (v/v) $\mathrm{N} 2$ supplement, 2\% (v/v) B27 supplement and penicillin/ streptomycin. Over the 14-day period of differentiation, N2/ B27 media were supplemented with $1 \mu \mathrm{M}$ all-trans retinoic acid (RA) and $1 \mu \mathrm{M}$ smoothened agonist (SAG; Millipore, Bedford, MA, USA). For the first 6 days, cells were also subjected to dual SMAD inhibition with $10 \mu \mathrm{M}$ SB431542 and 100 nM LDN (Stemgent, Lexington, MA, USA). On Day 7, dual SMAD inhibition was exchanged for $4 \mu$ M SU5402 (Stemgent, Lexington, MA, USA) and $5 \mu$ M DAPT (Selleck Chemicals, Houston, TX, USA) [52].

At Day 14, differentiated cells were dissociated with Accutase and plated onto poly-L-ornithine/laminin-coated 6-well plates (BD Biosciences, Franklin Lakes, NJ, USA) at a density of 100,000 cells $/ \mathrm{cm}^{2}$, or $13 \mathrm{~mm}$ diameter coverslips (No. 1.5, VWR, Stockholm, Sweden) at 40,000 cells/ $\mathrm{cm}^{2}$. MNAC cultures were maintained in MN culture media, consisting of Neurobasal, 1x NEAA, $2 \mathrm{mM}$ L-glutamine, $1 \%$ (v/v) N2 supplement, 2\% (v/v) B27 supplement, $0.4 \mathrm{mg} / \mathrm{L}$ ascorbic acid, $25 \mu \mathrm{M}$ glutamate, $25 \mu \mathrm{M}$ 2-mercaptoethanol, $1 \mu \mathrm{M}$ RA, $20 \mu \mathrm{M}$ Y-27632 (Abcam, Cambridge, UK) and penicillin/streptomycin. Cells were incubated in a humidified atmosphere at $37{ }^{\circ} \mathrm{C}$ supplemented with $5 \%(\mathrm{v} / \mathrm{v}) \mathrm{CO}_{2}$. At days 11-13 days after plating, (days 24-26 after the onset of differentiation), MNACs were exposed to different $\mathrm{O}_{2}$ tensions prior to analysis.

\section{Generation of patient-derived primary astrocytes}

A piece $(2 \mathrm{~cm})$ of the ventral horn from the thoracic spinal cord of a $S O D 1^{A 4 V}$ patient (Supplementary Table 1) was dissected at autopsy for cell isolation as described [41]. The tissue was diced and then dissociated using $2.5 \mathrm{U} / \mathrm{ml}$ papain and $0.5 \mathrm{U} / \mathrm{ml}$ Dispase (Stemcell Technology, Canada, Inc.) in 1 xHBSS supplemented with $40 \mu \mathrm{g} / \mathrm{ml}$ DNAse at $37^{\circ} \mathrm{C}$ for $45 \mathrm{~min}$ with mixing every $5 \mathrm{~min}$. Cells were dissociated using a P1000 pipette tip and then mixed with KnockOut DMEM/F12 media containing 10\% (v/v) foetal bovine serum (FBS), After filtering the cells through a $0.7 \mu \mathrm{m}$ cell strainer, they were pelleted by centrifugation at $500 \mathrm{~g}$ for $5 \mathrm{~min}$. The cell pellet was resuspended in DMEM/F12 $+10 \%$ (v/v) FBS and mixed with an equal volume of Percoll (GE Healthcare, Chicago, Illinois). The mixture was centrifuged at $20,000 \mathrm{~g}$ for $30 \mathrm{~min}$ at $4{ }^{\circ} \mathrm{C}$ and the flocculent layer above the red blood cell layer was collected, washed, pelleted and resuspended in primary cell media containing KnockOut DMEM/F12 + 10\% (v/v) FBS supplemented with $20 \mathrm{ng} /$ $\mathrm{ml}$ FGF-2, $20 \mathrm{ng} / \mathrm{ml}$ EGF, $20 \mathrm{ng} / \mathrm{ml}$ PDGF-AB (all from Peprotech, Rocky Hill, NJ), 2 mM GlutaMAX Supplement, 1x StemPro Neural Supplement and penicillin/streptomycin. The cells were cultured on CELLstart-coated plates and after $24 \mathrm{~h}$ the medium was replaced with serum-free primary cell media. Half of the medium was replaced every 2 days over 4-5 weeks until the cells reached $80 \%$ confluence. The cells were then passaged, expanded and plated either in coated 6-well plates (BD Biosciences, Franklin Lakes, NJ, USA), for exposure to different $\mathrm{O}_{2}$ tensions, or on $13 \mathrm{~mm}$ coated coverslips (No. 1.5, VWR, Stockholm, Sweden) for immunocytochemistry.

\section{Exposure to different oxygen tensions}

Fibroblasts were plated at $8000-16,000$ cells $/ \mathrm{cm}^{2}$ in 6 -well plates (BD Biosciences, Franklin Lakes, NJ, USA) and incubated in a humidified atmosphere at $37{ }^{\circ} \mathrm{C}$ with $5 \%(\mathrm{v} / \mathrm{v})$ $\mathrm{CO}_{2}$. After reaching 75-85\% confluence, the media were replaced prior to exposure to different $\mathrm{O}_{2}$ tensions. Differentiated MNACs were exposed to different $\mathrm{O}_{2}$ concentrations without a media change. For $\mathrm{O}_{2}$ tensions lower than 
$19 \%$, cells were incubated in a sealed, humidified chamber (Biospherix, Lacona, NY, USA) gassed with gas mixtures $\left(1-10 \% \mathrm{O}_{2}, 5 \% \mathrm{CO}_{2}, 94-85 \% \mathrm{~N}_{2}\right)$ at $37^{\circ} \mathrm{C}$. The $\mathrm{O}_{2}$ concentration was maintained using a ProOx P110 oxygen controller (Biospherix, Lacona, NY, USA) supplied with $\mathrm{N}_{2}$ gas. For each experiment, cells were also cultured in parallel under humidified atmospheric $\mathrm{O}_{2}\left(19 \% \mathrm{O}_{2}, 5 \% \mathrm{CO}_{2}, 76 \%\right.$ $\mathrm{N}_{2}$ ) in a standard tissue culture incubator.

\section{Immunocytochemistry}

Cells were fixed in 3.8\% (w/v) formaldehyde for $10 \mathrm{~min}$ at room temperature, and blocked with $10 \%(\mathrm{v} / \mathrm{v})$ FBS in PBS containing $0.1 \%$ (v/v) Triton X-100 for $1 \mathrm{~h}$ at room temperature. Cells were incubated with primary antibodies overnight at $4{ }^{\circ} \mathrm{C}$. The primary antibodies used were: anti-neuron-specific class III beta-tubulin (TUBB3, TUJ1, 1:7500, Covance Inc. Princeton, NJ, USA), microtubuleassociated protein 2 (MAP2; 1:500, Millipore, Bedford, MA, USA), SMI32 (1:1000, Covance Inc. Princeton, NJ, USA), ISL1/2 (39.4D5, 1:5, developed by T.M. Jessell and S. Brenner-Morton was obtained from the Developmental Studies Hybridoma Bank, created by the NICHD of the NIH and maintained at The University of Iowa, Department of Biology, Iowa City, IA 52242), S100ß (1:200) and vimentin (1:1000 Progen, Heidelberg, Germany). The following day, coverslips were washed and incubated with Alexa-Fluor conjugated secondary antibodies $(1: 1000)$ for $1 \mathrm{~h}$ at room temperature, and nuclei were counterstained with 4',6-diamidino-2-phenylindole (DAPI; $0.3 \mu \mathrm{M}$ ). Cells were mounted in Aqua-Polymount (Polysciences, Inc., Warrington, PA, USA).

\section{In vitro cell cytotoxicity assays}

Dead cells that had lost plasma membrane integrity were quantified using the luminogenic substrate AAF-Glo (CytoTox-Glo Cell Viability Assay, Promega, Madison, WI, USA) as previously described [51]. Cell viability was calculated by subtracting the luminescence signal obtained before permeabilization with digitonin, from the luminescence signal obtained afterward, according to the manufacturer's protocol.

Cellular ATP content was determined using the CellTiterGlo Luminescent Cell Viability Assay (Promega, Madison, WI, USA).

\section{Proteasome activity assay}

A cell-based luminescent proteasome assay (ProteasomeGlo, Promega, Madison, WI, USA) was used to measure chymotrypsin-like proteasome activity as described [51]. The assay contains the luminogenic peptide substrate
Suc-LLVY-aminoluciferin for determination of chymotrypsin-like activity of the proteasome.

\section{Cell extracts}

Cells were washed with $37{ }^{\circ} \mathrm{C}$ PBS containing $40 \mathrm{mM}$ iodoacetamide (IAM), which blocks reduced cysteine residues via alkylation to prevent oxidation of reduced C57-C146 disulfide bonds during sample processing [78]. The cells were detached with trypsin and then washed with PBS containing $40 \mathrm{mM}$ IAM and $0.5 \%$ (v/v) FBS. After centrifugation of the suspension at $500 \mathrm{~g}$ for $5 \mathrm{~min}$, the cell pellet was collected and snap frozen on dry ice and stored in a $-80^{\circ} \mathrm{C}$ freezer.

Cell pellets were thawed rapidly in a water bath at $25^{\circ} \mathrm{C}$ for $1 \mathrm{~min}$ and then lysed in ice-cold PBS containing Complete EDTA-free protease inhibitor cocktail (Roche Diagnostics, Mannheim, Germany), $40 \mathrm{mM}$ IAM and $0.5 \%$ (v/v) Nonidet P-40 (NP-40) using a Sonifier Cell Disrupter (Branson, Danbury, CT, USA). Lysates were centrifuged at $20,000 \mathrm{~g}$ for $30 \mathrm{~min}$ at $4{ }^{\circ} \mathrm{C}$ and the supernatant was collected. The protein content of the cell lysate supernatant was determined using the BCA Protein Assay Kit. Disordered SOD1 was then analyzed immediately by misELISA (see below). Pellets were retained and snap frozen on dry ice and stored at $-80{ }^{\circ} \mathrm{C}$ for the subsequent analysis of SOD1 in detergent-insoluble aggregates (see below).

\section{Analysis of disordered and total SOD1 by ELISA}

Disordered SOD1 was quantified in cell extracts using a specific ELISA (misELISA), described previously [76, 77]. The capture antibody was raised in rabbits against a peptide corresponding to aa 24-39 of the human SOD1 sequence. This antibody reacts only with highly disordered SOD1 species and lacks affinity for the natively folded protein [11, 31, 33]. A goat anti-human SOD1 antibody was used as a detection antibody. It was raised against SOD1 that had been denatured by incubation with guanidinium chloride and EDTA, and reacts preferentially with the disordered/unfolded protein [76]. For calibration of the misELISA, brain and spinal cord tissue from a Tg mouse expressing human SOD ${ }^{\mathrm{G} 127 \mathrm{X}}$ was homogenized in 25 volumes $10 \mathrm{mM}$ potassium phosphate buffer, pH 7.0 in $0.15 \mathrm{M} \mathrm{NaCl}$, containing Complete Protease Inhibitor Cocktail (Roche Diagnostics, Mannheim, Germany) and $40 \mathrm{mM}$ IAM. After centrifugation at 20,000 $\mathrm{g}$ at $4{ }^{\circ} \mathrm{C}$, the supernatant was divided into aliquots that were stored at $-80^{\circ} \mathrm{C}$. One unit of disordered SOD1 is defined as the amount present in $1 \mathrm{~g}$ wet weight of the original human SOD $1^{\text {G127X }}$ standard.

The misELISA only detects disordered SOD1 species. There is no response to holoSOD1 or SOD1s that lack $\mathrm{Cu}$ and/or the C57-C146 disulfide bond, as long as the 
polypeptide is natively folded. Cell extracts are incubated for $1 \mathrm{~h}$ at $23{ }^{\circ} \mathrm{C}$ with the capture antibody. This temperature was selected as optimal because at the physiological $37^{\circ} \mathrm{C}$, some folded SOD1 species undergo continuous unfolding in highly diluted cell and tissue extracts, such as those analyzed here [77]. In addition, an increase in disorder at $37{ }^{\circ} \mathrm{C}$ compared to $23{ }^{\circ} \mathrm{C}$ is expected to show considerable variation between different SOD1s. For instance, the fulllength $\mathrm{SOD} 1^{\mathrm{A} 4 \mathrm{~V}}$ and $\mathrm{SOD} 1^{\mathrm{G} 93 \mathrm{~A}}$ mutants show a significant degree of unfolding at $23{ }^{\circ} \mathrm{C}$ when $\mathrm{Cu}, \mathrm{Zn}$ and the disulfide bond are removed (apo, disulfide-reduced SOD1). However, for SOD $1^{\mathrm{WT}}$ and stable mutants, the apo, disulfidereduced forms melt at temperatures exceeding $40{ }^{\circ} \mathrm{C}$ [64]. Hence, more stable variants would show greater proportional increases in disorder at $37{ }^{\circ} \mathrm{C}$ than their unstable counterparts. SOD $1^{\mathrm{G} 127 \mathrm{X}}$ and SOD $1^{\mathrm{D} 125 \mathrm{Tfs} * 24} \mathrm{C}$-terminal truncation mutants cannot fold natively and are intrinsically disordered. However, since they lack the C-terminal end, the truncation mutants are also expected to react less extensively with the detection antibody, which is raised against the entire denatured hSOD1 protein. Finally, mutations can also influence the conformation of immature SOD1 states, which could affect antibody reactivity $[67,70]$. Hence, actual levels of disordered SOD1 at the physiological $37{ }^{\circ} \mathrm{C}$ are not mirrored equally for all SOD1 variants, and misELISA results are not directly comparable between cell lines expressing different SOD1s. However, for a given cell line expressing the same SOD1 variant, the effects of different $\mathrm{O}_{2}$ tensions on the levels of disordered SOD1 can be determined.

Following misELISA, cell extracts were snap frozen and subsequently analysed for total SOD1 with a sandwich ELISA based on rabbit capture and goat detection antibodies raised against native human SOD1 [76]. These antibodies bind to both native and disordered SOD1 with similar affinities.

\section{Design and analysis of misELISA experiments}

All sets of independent experiments were conducted with cultures of each cell line grown in triplicate wells (i.e. three technical replicates) for each $\mathrm{O}_{2}$ tension. This was repeated on at least three occasions (i.e. three independent experiments). To analyze differences in absolute misELISA values, data from all replicates for one condition $\left(19 \%\right.$ or low $\left.\mathrm{O}_{2}\right)$ were pooled for statistical analyses (see below) (fibroblasts/ primary astrocytes, Fig. 3a/b; MNACs, Fig. 4b). To compensate for variations in cell density and other methodological variations in sample preparation and analysis, we also analyzed the ratio of disordered SOD1 at 19\% versus low $\mathrm{O}_{2}$. In this case, the mean of absolute misELISA values at $19 \%$ $\mathrm{O}_{2}$ was used to normalize ELISA values within all samples belonging to the same set (fibroblasts/primary astrocytes,
Fig. 3c/d; MNACs, Fig. 4c), prior to statistical analyses (see below).

\section{Western blotting}

Western blots were performed on Any $\mathrm{kD}$ or $18 \%$ (w/v) Criterion TGX precast gels (BioRad Laboratories, Hercules, CA, USA) as previously described [51]. Primary antibodies (see below) were incubated overnight at $4{ }^{\circ} \mathrm{C}$. Horseradish peroxidase (HRP)-conjugated secondary antibodies (antimouse or anti-rabbit IgG; 1:10,000, Dako, Glostrup, Denmark) were incubated for $1 \mathrm{~h}$ at room temperature. ECL Select reagent (GE Healthcare Biosciences, Piscataway, NJ, USA) was used to detect the signal, which was recorded on a ChemiDoc Touch apparatus (BioRad Laboratories, Hercules, CA, USA) and analyzed using ImageLab software (BioRad Laboratories, Hercules, CA, USA).

The primary antibodies used for western blotting were; rabbit anti-human SOD1 antibodies raised against peptides corresponding to aa $24-39(2.3 \mu \mathrm{g} / \mathrm{ml})$, aa $57-72(1.6 \mu \mathrm{g} /$ $\mathrm{ml})$, aa $144-153(5.2 \mu \mathrm{g} / \mathrm{ml})$ and aa $123-127$ GQRWK (4.8 $\mu \mathrm{g} / \mathrm{ml}, \mathrm{G127X}$-specific) [46], rabbit anti-CCS raised against peptides corresponding to aa 252-270 of the human CCS sequence (CCS, $0.9 \mu \mathrm{g} / \mathrm{ml}$ ) [46], rabbit anti-CCS (1:1000 Santa Cruz Biotechnology, Dallas, TX, USA), rabbit anti-glutaredoxin-1 (1:250, Abcam, Cambridge, UK), mouse anti- $\beta$-actin (1:200,000; Millipore, Bedford, MA, USA) and rabbit anti-GAPDH (1:1000, Abcam, Cambridge, UK).

\section{Human SOD1 standards}

For quantification by total SOD1 ELISA, or full-length SOD1 by western blotting, a human hemolysate was used with known SOD1 content calibrated against pure human SOD1, the concentration of which had been determined by quantitative amino acid analysis [57]. For quantification by misELISA, or SOD $1^{\mathrm{G} 127 \mathrm{X}}$ by western blotting, an hSOD1 ${ }^{\mathrm{G} 127 \mathrm{X}} \mathrm{Tg}$ mouse extract was used in which the SOD $1^{\mathrm{G} 127 \mathrm{X}}$ content had been determined by western blotting using the human SOD1-specific aa 24-39 antibody.

\section{Quantification of disulfide-reduced and-oxidized SOD1}

The proportions of disulfide-reduced and -oxidized SOD1 were determined using western blotting (see above) following polyacrylamide gel electrophoresis under non-reducing conditions, i.e. by omitting reductant and adding $40 \mathrm{mM}$ IAM to the sample buffer, as previously described $[46,77$, 78]. 


\section{Immunocapture}

The same rabbit anti-human SOD1 antibody raised against aa 24-39 of SOD1 used in the misELISA was cross-linked to Dynabeads ${ }^{\circledR}$ M-270 Epoxy with the Dynabeads Antibody Coupling Kit. Beads were recovered with a magnet, washed with the supplied buffers to remove unbound antibody and equilibrated with PBS containing Complete EDTA-free protease inhibitor cocktail (Roche Diagnostics, Mannheim, Germany), $40 \mathrm{mM}$ IAM and 0.5\% (v/v) NP-40. Antibodycoated beads were incubated with $20,000 \mathrm{~g}$ cell lysate supernatants (see above) for $1 \mathrm{~h}$ at $23{ }^{\circ} \mathrm{C}$. Beads were washed five times with PBS containing the Complete EDTA-free protease inhibitor cocktail (Roche Diagnostics, Mannheim, Germany), 40 mM IAM and 0.5\% (v/v) NP-40 and samples were eluted by boiling in 1x Sample Buffer containing $40 \mathrm{mM}$ IAM. A proportion of the input and non-bound fractions (1/40th), as well as the entire immunocaptured fractions, were analyzed using non-reduced western blotting to determine the relative proportions of reduced and oxidized SOD1.

\section{Analysis of reduced and oxidized glutathione}

GSH and GSSH were quantified by LC-MS [25]. After exposure of MNACs and fibroblasts to different $\mathrm{O}_{2}$ tensions $\left(1-2-19 \% \mathrm{O}_{2}\right)$ for $24 \mathrm{~h}$ in 6-well plates, media were aspirated and $300 \mu \mathrm{L}$ of ice-cold extraction mixture $(0.25 \mu \mathrm{M}$ glutathione (glycine- ${ }^{13} \mathrm{C}_{2},{ }^{15} \mathrm{~N}$; GSH internal standard), $2.5 \%$ metaphosphoric acid, $1 \mathrm{mM}$ EDTA and $0.1 \%$ formic acid) were added immediately to the cells. After scraping, the resulting cell suspensions were snap-frozen and stored at $-80{ }^{\circ} \mathrm{C}$ until analysis.

A tungsten bead was added to each tube and the frozen samples were homogenized immediately in a bead mill (Retsch MM400) at 30 oscillations/s for $1 \mathrm{~min}$, followed by centrifugation at $22,000 \mathrm{~g}$ for $20 \mathrm{~min}$. The resulting supernatant $(50 \mu \mathrm{L})$ was transferred to a $\mathrm{LC}-\mathrm{MS}$ vial and $1 \mu \mathrm{L}$ was injected and analyzed by LC-ESI-MSMS (1290 Infinity system from Agilent Technologies, with an Acquity UPLC HSS T3 column, thermostatted to $40{ }^{\circ} \mathrm{C}$ and coupled to an Agilent 6490 Triple quadrupole mass spectrometer). The analysis was performed essentially as described [18] by comparison to reduced glutathione (GSH) and oxidized glutathione (GSSG) solutions made in water $(2.5 \mathrm{mM}$ metaphosphoric acid, $1 \mathrm{mM}$ EDTA, $0.1 \%$ formic acid) at twelve different calibration concentrations $(0.01-10 \mu \mathrm{M})$ and containing the GSH internal standard.

GSH and GSSG concentrations were normalized to the protein content of the corresponding 22,000 $\mathrm{g}$ pellets after extraction. Pellets were resuspended by sonication/boiling in 1x Sample Buffer. Protein estimation was performed using the BCA Protein Assay Kit and bovine serum albumin standards boiled in 1x Sample Buffer.

\section{Cycloheximide treatment}

Fibroblasts were exposed to $19 \% \mathrm{O}_{2}$ or $1 \% \mathrm{O}_{2}$ as described above in the presence and absence of the protein synthesis inhibitor cycloheximide (CHX; $50 \mu \mathrm{g} / \mathrm{ml}$ ) for $24 \mathrm{~h}$, prior to harvest and analysis by misELISA and total SOD1 ELISA.

\section{Quantification of SOD1 in detergent-insoluble aggregates}

Pellets were thawed on ice and washed twice by centrifugation at $20,000 \mathrm{~g}$ for $30 \mathrm{~min}$ at $4{ }^{\circ} \mathrm{C}$ in cold PBS containing $0.5 \%(\mathrm{v} / \mathrm{v}) \mathrm{NP}-40$ to remove remaining detergent-soluble proteins. The material remaining in the pellet was used to determine the amount of detergent-insoluble/aggregated SOD1 by western blotting by comparison to a human SOD1 standard (see above). The amount of aggregated SOD1 in the detergent-insoluble fraction was expressed as a percentage of soluble SOD1 present in the corresponding cell extract, determined by total SOD1 ELISA.

\section{Statistical analyses}

Statistical analyses were performed using Prism version 6.00 (GraphPad, La Jolla, CA, USA). To test for statistical significance between two groups, Mann-Whitney $\mathrm{U}$ test was used. For ratio analysis where data was normalized to the mean of $19 \% \mathrm{O}_{2}$, the degree of freedom $(d f)$ was adjusted with $d f-1$. For statistical significance testing between multiple groups, Kruskal-Wallis test followed by Dunn's post hoc test was used. Alpha $\leq 0.05$ was used as the cut-off for significance. All values are given as mean \pm SD.

\section{Results}

\section{Low oxygen tension promotes SOD1 disorder in patient-derived cells}

Previously, we have used dermal fibroblasts from ALS patients as a cell culture model to study disordered SOD1 under physiological levels of SOD1 expression [51]. Cells cultured in vitro are typically maintained in humidified ambient air supplemented with 5\% (v/v) $\mathrm{CO}_{2}$, resulting in an $\mathrm{O}_{2}$ tension of approximately $19 \%$. However, under normal conditions, $\mathrm{O}_{2}$ tensions in the CNS are much lower, ranging between 0.2 and 5\% [29, 55]. Moreover, various pathological conditions may lead to further reductions in local $\mathrm{O}_{2}$ tension. Therefore, we investigated the levels of disordered SOD1 in fibroblasts exposed to lowered $\mathrm{O}_{2}$ tensions for $24 \mathrm{~h}$ 


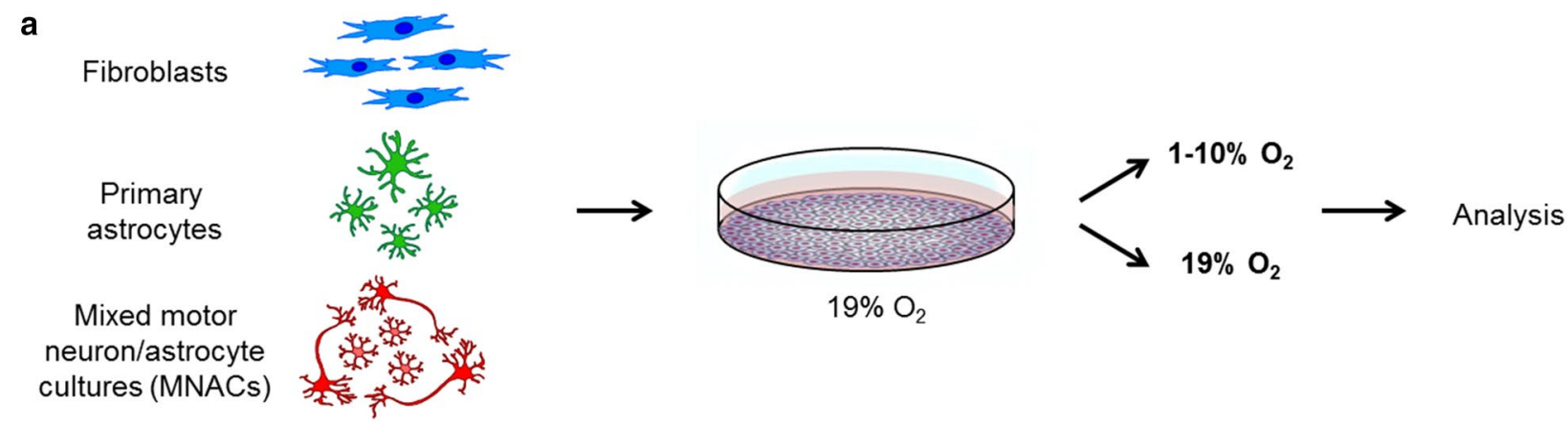

b

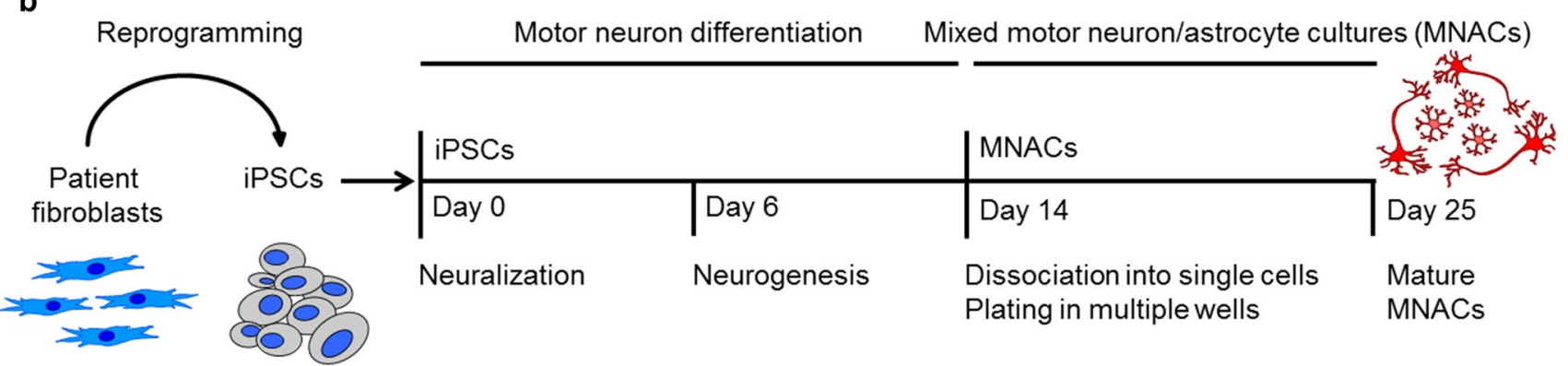

Fig. 1 Experimental overview and generation of mixed motor neuron and astrocyte cultures (MNACs) derived from induced pluripotent stem cells (iPSCs). a Patient-derived fibroblasts, primary spinal cord ventral horn astrocytes and iPSC-derived MNACs were exposed to different $\mathrm{O}_{2}$ tensions for $24 \mathrm{~h}$ prior to analysis. b Patient-derived fibroblasts were reprogrammed to iPSCs using the four Yamanaka

(Fig. 1a). We selected lines expressing a large number of different SOD1 variants with diverse molecular properties (Supplementary Table 1), to correlate these properties with potential increases in disordered SOD1, which we quantified with a specific ELISA (misELISA) [76].

Lines carrying the SODI $1^{\text {N86S }}$ and SOD1 $1^{\text {E78_R79insSI }}$ mutations showed distinct $\mathrm{O}_{2}$ concentration-dependent responses in disordered SOD1. Increase in disordered SOD1 was detected from $3 \%$ but was most significant at $1 \% \mathrm{O}_{2}$ (Fig. 2a). However, no increases in disordered SOD1 were found in a line carrying the $S O D 1^{G 127 X}$ mutation, which results in a C-terminally truncated protein that cannot fold properly due to a disrupted $\beta$-barrel and absence of the C57-C146 disulfide bond (Fig. 2a). Quantification of total SOD1 relative to total protein was performed to confirm that increases in disordered SOD1 were not due to increased SOD1 expression in response to low $\mathrm{O}_{2}$ tensions (Supplementary Fig. 1).

We next investigated the temporal response at $1 \% \mathrm{O}_{2}$ and detected significant increases in disordered SOD1 at 4-8 h, which were sustained up to $24 \mathrm{~h}$ (Fig. 2b). To address whether the increase in disordered SOD1 was reversible, we examined different time points after returning cells from $24 \mathrm{~h}$ at $1 \% \mathrm{O}_{2}$ to $19 \% \mathrm{O}_{2}$. A rapid reversal was observed factors and then differentiated to a forelimb level, ventral spinal cord identity over 14 days. At Day 14, differentiated cells were dissociated to single cells and plated onto poly-L-ornithine/laminin-coated wells and matured for 10 more days. MNACs were used for $\mathrm{O}_{2}$ tension experiments at Day 25

in the SOD1 ${ }^{\mathrm{G} 93 \mathrm{~A}}$ line with a half-life for disordered SOD1 of $\sim 30 \mathrm{~min}$, returning to baseline after $4 \mathrm{~h}$ (Fig. 2c). Reversal of the increase in disordered SOD $1^{\mathrm{WT}}$ in a control line was more rapid (Fig. 2c). No significant effects were seen in the SOD $1^{\text {G127X }}$ line (Fig. 2c). Hence, we concluded that the disordered SOD1 response was inversely proportional to $\mathrm{O}_{2}$ tension and was also time-dependent, reversible, and appeared to require the C57-C146 disulfide bond. Amongst the conditions tested in fibroblasts, the most significant response observed was at $1 \% \mathrm{O}_{2}$ for $24 \mathrm{~h}$.

We proceeded to investigate the response in disordered SOD1 under the same conditions in a panel of non-disease control and patient-derived fibroblast lines (Supplementary Table 1). We also generated primary astrocytes from the ventral spinal cord of a $S O D 1^{A 4 V}$ ALS patient (Fig. 1a, Supplementary Fig. 2, and Supplementary Table 1). When comparing absolute levels of disordered SOD1 (Fig. 3a and b), or the ratio of disordered SOD1 at 1\% versus $19 \% \mathrm{O}_{2}$ (Fig. 3c and d), significant increases ranging from 1.6 to 3.5 -fold were seen in all lines that carried full-length mutant SOD1s. Significant increases of lesser magnitude were also observed in most control lines, as well as in those from patients carrying ALS-linked $C$ 9orf72, FUS or TBK1 mutations, which only contain SOD1 ${ }^{\mathrm{WT}}$. Analysis of disordered SOD1 ratios 
Fig. 2 Concentration- and time-dependent appearance of disordered SOD1 in response to low $\mathrm{O}_{2}$ tensions. Disordered SOD1 was quantified in fibroblast extracts by misELISA and normalized to total protein. a $\mathrm{O}_{2}$ concentration- $(1-2-3-$ 4-5-19\%) and b time- - (1-48-24 h) dependent increases in disordered SOD1 in fibroblast lines. $\mathbf{c}$ Reversal of the response in disordered SOD1 following transfer of cultures from $1 \%$ $\mathrm{O}_{2}$ for $24 \mathrm{~h}$ to $19 \% \mathrm{O}_{2}$ for the time indicated. a-c Data are expressed as the mean \pm SD of nine technical replicates from three independent experiments, $* p<0.05, * * p<0.01$, $* * * p<0.001, * * * * p<0.0001$, analyzed by Kruskal-Wallis test followed by Dunn's test a

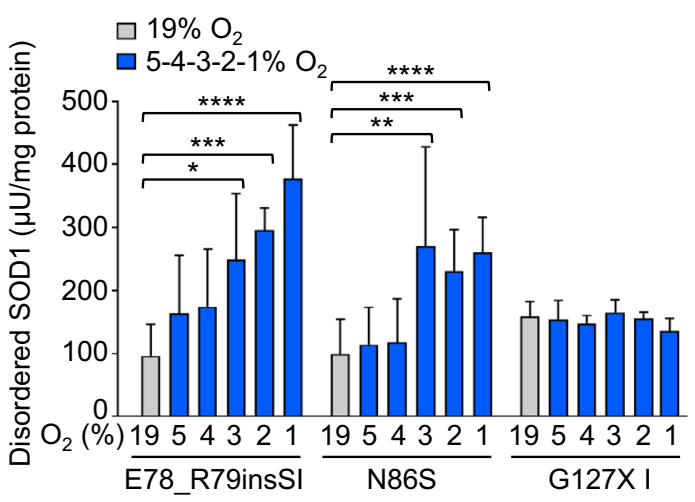

c

$\square 19 \% \mathrm{O}_{2}$ $\square 1 \% \mathrm{O}_{2}$ 圈 $1 \% \mathrm{O}_{2}+19 \% \mathrm{O}_{2}$ (indicated time) G93A

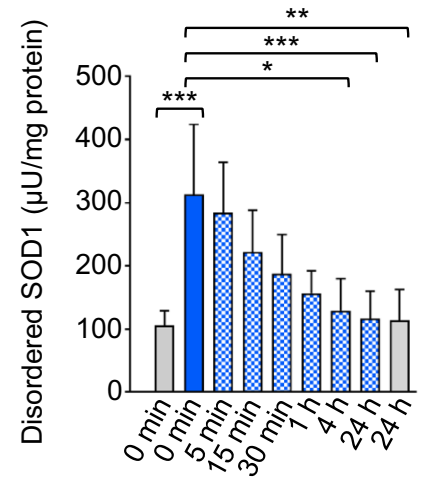

b

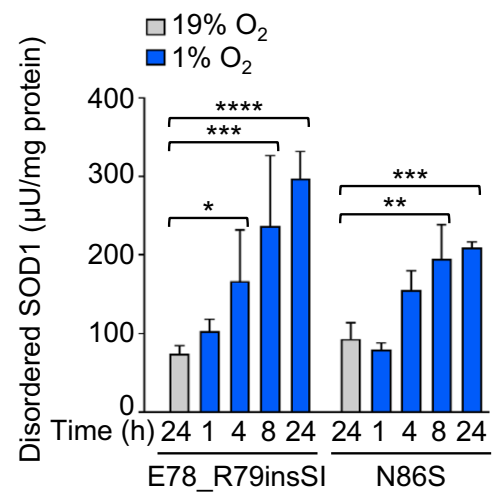

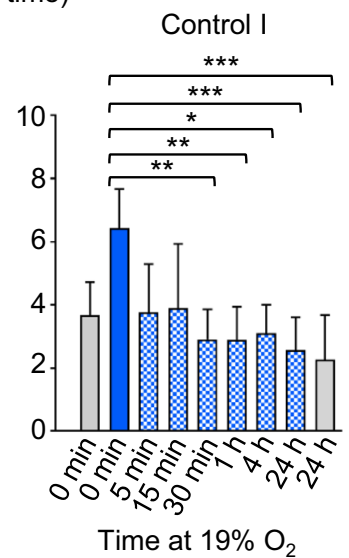

G127X I

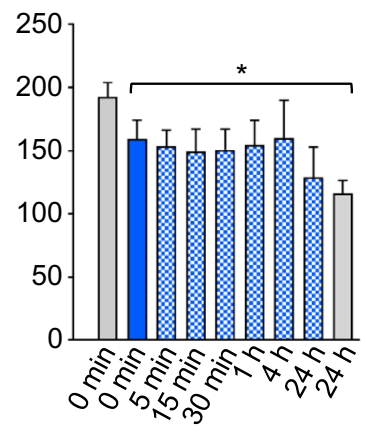

highlighted significant increases in all lines, apart from those carrying C-terminal SOD1 truncation mutations and the absence of C146: SOD $1^{G 127 X}$ and SOD1 $1^{\text {D125Tfs*2 }}$. This supported the earlier conclusion that the response in disordered SOD1 to low $\mathrm{O}_{2}$ requires the C57-C146 disulfide bond.

\section{An enhanced response of disordered SOD1 in motor neuron/astrocyte cultures}

Since ALS preferentially targets the motor system, we reprogrammed a subset of the patient-derived fibroblast lines to iPSCs and differentiated these to MNACs (Fig. 1b and Supplementary Table 1). Recently we have found that levels of disordered SOD1 are enhanced in MNACs compared to their corresponding fibroblasts, iPSCs and iPSC-derived sensory neurons (unpublished data). After 10 days in culture postdifferentiation (Day 25; Fig. 1b), MNACs contained 5\% neurons expressing tubulin beta-3 chain (TUBB3; Supplementary Fig. 3a and b) and $\sim 95 \%$ astrocytes expressing astrocyte markers (unpublished data). A large proportion of neurons (78-84\%) co-expressed the motor neuron markers ISL LIM homeobox 1/2 (ISL1/2) and non-phosphorylated
neurofilament-H (SMI32), representing a limb innervating subtype that are highly susceptible to ALS [2].

We first titrated the dose-response in disordered SOD1 to $\mathrm{O}_{2}$ tension in MNACs from control, SOD $1^{\mathrm{A} 4 \mathrm{~V}}$ and SOD1 ${ }^{\mathrm{G} 93 \mathrm{~A}}$ lines. A significant increase in disordered SOD1 was detected at $\leq 4 \%$ and was maximal at $2 \% \mathrm{O}_{2}$, which was enhanced in MNACs compared to fibroblasts in all three lines (Fig. 4a). Under the same conditions used for fibroblasts $\left(1 \% \mathrm{O}_{2}\right.$ for $\left.24 \mathrm{~h}\right)$, a significant degree of axonal fragmentation was observed (data not shown), indicative of neuronal stress. However, since axonal morphology (Supplementary Fig. 3b), cellular ATP levels (Supplementary Fig. 4a) and viability (Supplementary Fig. 4b) were not significantly affected by exposure to $2 \% \mathrm{O}_{2}$ for $24 \mathrm{~h}$, this was used to investigate the response in disordered SOD1 in MNACs.

Large increases in disordered SOD1, ranging up to tenfold, were observed in MNACs following exposure to $2 \%$ $\mathrm{O}_{2}$ for $24 \mathrm{~h}$ (Fig. $4 \mathrm{~b}$ and c). The largest effects were found in several of the lines expressing full-length mutant SOD1s (E78_R79insSI, N86S, A4V, and G93A). However, in contrast to fibroblasts, a robust 3 to 4 -fold increase was also seen 

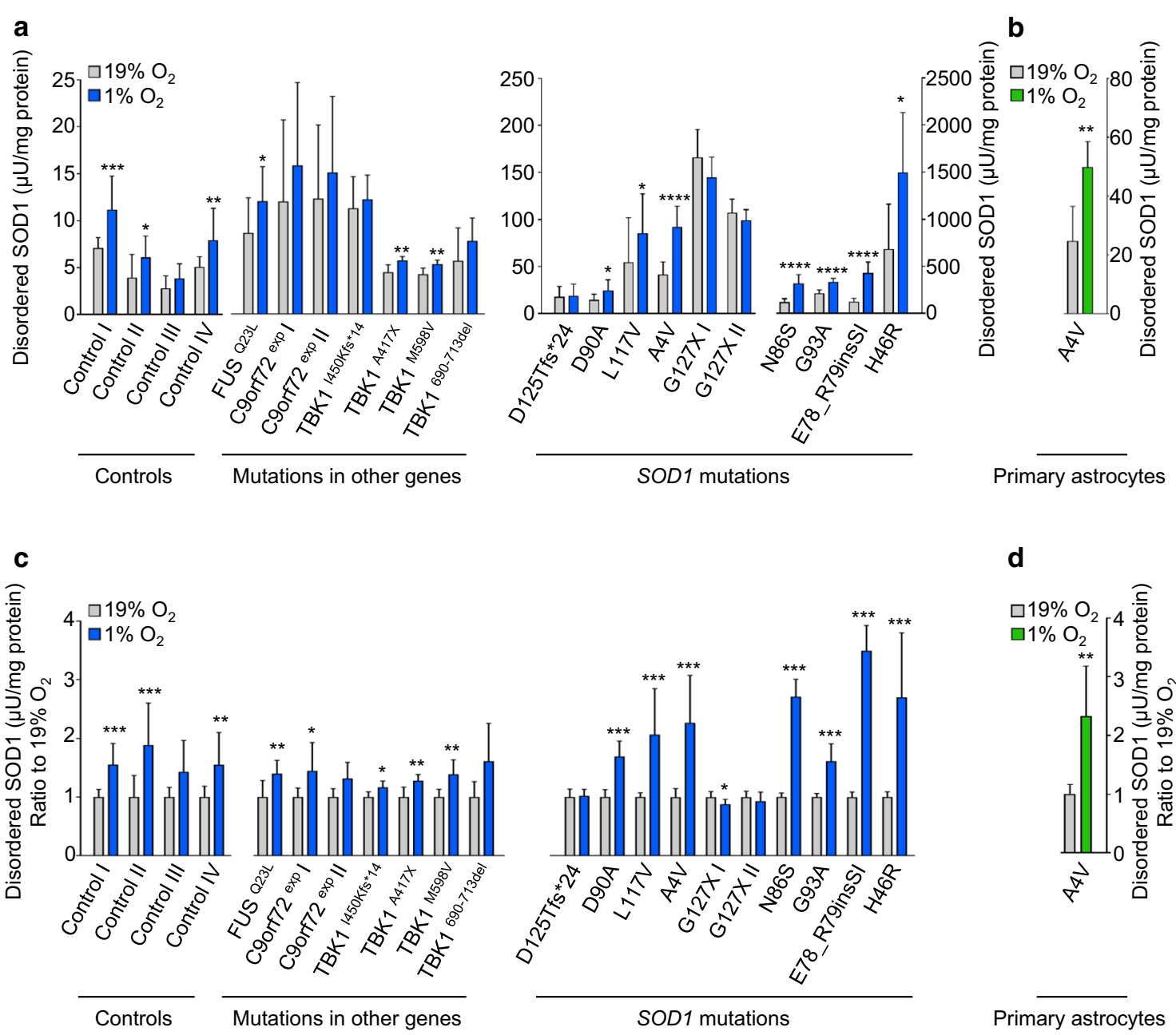

d

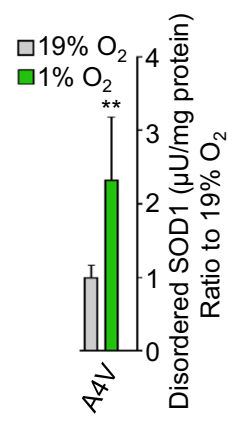

Primary astrocytes

Fig. 3 Response in disordered SOD1 to low oxygen tension in patient-derived cells. Following exposure to $1 \% \mathrm{O}_{2}$ for $24 \mathrm{~h}$, disordered SOD1 quantified in cell extracts by misELISA, normalized to total protein; a Patient-derived fibroblast lines, b Primary astrocytes. c and d Data presented as a ratio to the level present in replicate cultures maintained at $19 \% \mathrm{O}_{2}$ for $24 \mathrm{~h}$. c Patient-derived fibroblast lines, $\mathbf{d}$ Primary astrocytes. $\mathbf{a}-\mathbf{d}$ Data are expressed as the mean \pm SD

in controls expressing SOD $1^{\mathrm{WT}}$ and in MNACs that were heterozygous for $S O D 1^{G 127 X}$ or $S O D 1^{D 125 T f * * 24}$ mutations and were present when comparing either absolute levels of disordered SOD1 (Fig. 4b) or the ratio (Fig. 4c) of disordered SOD1 within lines at $2 \%$ versus $19 \% \mathrm{O}_{2}$. The increases in disordered SOD1 in MNACs carrying SOD1 C-terminal truncation mutations are likely to represent SOD $1{ }^{\mathrm{WT}}$, since the level of mutant protein did not increase in the SOD1 ${ }^{\mathrm{G} 127 \mathrm{X}}$ line (Supplementary Fig. 5b).

Our previous study of patient-derived fibroblasts showed that disordered SOD1 is primarily degraded by the proteasome [51]. However, exposure to low $\mathrm{O}_{2}$ tension did not lead to a reduction in proteasome activity in MNAC extracts (Supplementary Fig. 6). Nor were there increases in SOD $1^{\text {G127X }}$ protein in either soluble (Supplementary Fig. 5) of nine to 15 technical replicates from three to five independent experiments, $* p<0.05, * * p<0.01, * * * p<0.001, * * * * p<0.0001$, analyzed by Mann-Whitney U test. $\mathbf{c}$ and $\mathbf{d}$ The degree of freedom $(d f)$ was adjusted with $d f-1$. Blue bars $=$ fibroblasts, green bars $=$ primary astrocytes, grey bars $=$ corresponding cell lines cultured at $19 \%$ $\mathrm{O}_{2}$

or detergent-insoluble (Supplementary Fig. 11b) fractions, which both increased greatly upon proteasome inhibition [51]. Inhibition of the proteasome also leads to copious

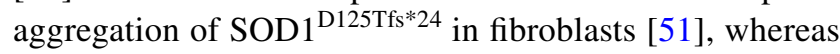
no changes were found here in response to low $\mathrm{O}_{2}$ tension (see below; Fig. 8 and Supplementary Fig. 11a). Hence, increases in disordered SOD1 at low $\mathrm{O}_{2}$ tensions could not be attributed to a reduction in proteasome activity.

\section{Low oxygen tension promotes reductive cleavage of the disulfide bond}

We have shown that reduction of the C57-C146 bond is a prerequisite for the formation of disordered SOD1 in the 
a
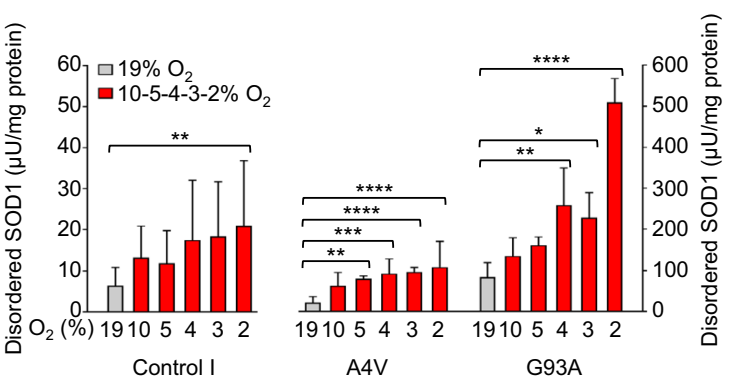

b

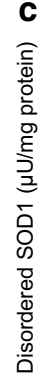
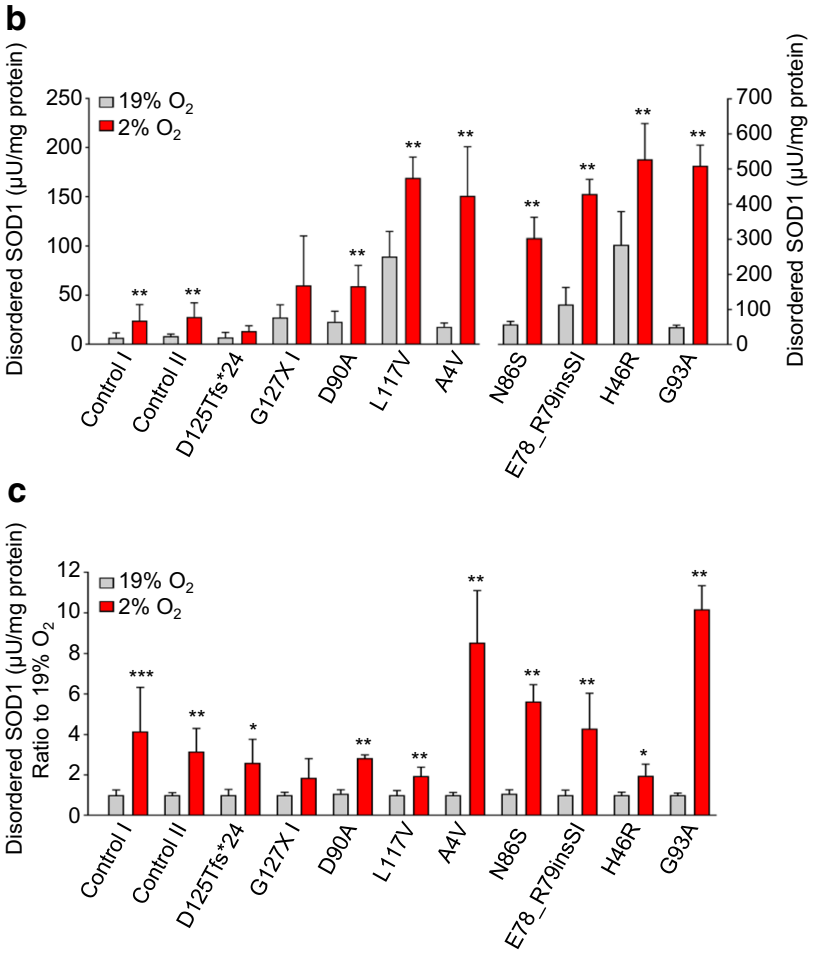

Fig. 4 Response in disordered SOD1 to low oxygen tension is enhanced in patient-derived MNACs. Disordered SOD1 was quantified in MNAC extracts by misELISA and normalized to total protein. a $\mathrm{O}_{2}$ tension (2-3-4-5-10-19\%) - dependent increases in disordered SOD1. Data are expressed as the mean \pm SD of six technical replicates from two independent differentiations. b Disordered SOD1 was quantified in extracts by misELISA and normalized to total protein from a panel of MNACs following exposure to $2 \% \mathrm{O}_{2}$ for $24 \mathrm{~h}$. c Data presented as a ratio to the level present in replicate cultures maintained at $19 \% \mathrm{O}_{2}$ for $24 \mathrm{~h}$. a-c Data are expressed as the mean $\pm \mathrm{SD}$ of six to 18 technical replicates from two to six independent differentiations, $* p<0.05, * * p<0.01$, ***p $p<0.001$, analyzed by MannWhitney U test. $\mathbf{c}$ The degree of freedom $(d f)$ was adjusted with $d f-1$

CNS $[77,78]$. To examine the status of the disulfide bond in MNACs we determined the proportions of disulfidereduced and oxidized SOD1 by non-reduced western blotting (Fig. $5 \mathrm{a}$ and b). Culture at $2 \% \mathrm{O}_{2}$ for $24 \mathrm{~h}$ resulted in significant increases in disulfide-reduced SOD1, both in control lines expressing SOD ${ }^{\mathrm{WT}}$ and those expressing a

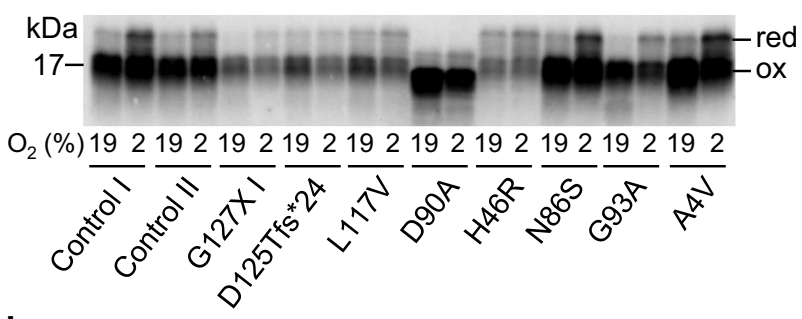

b

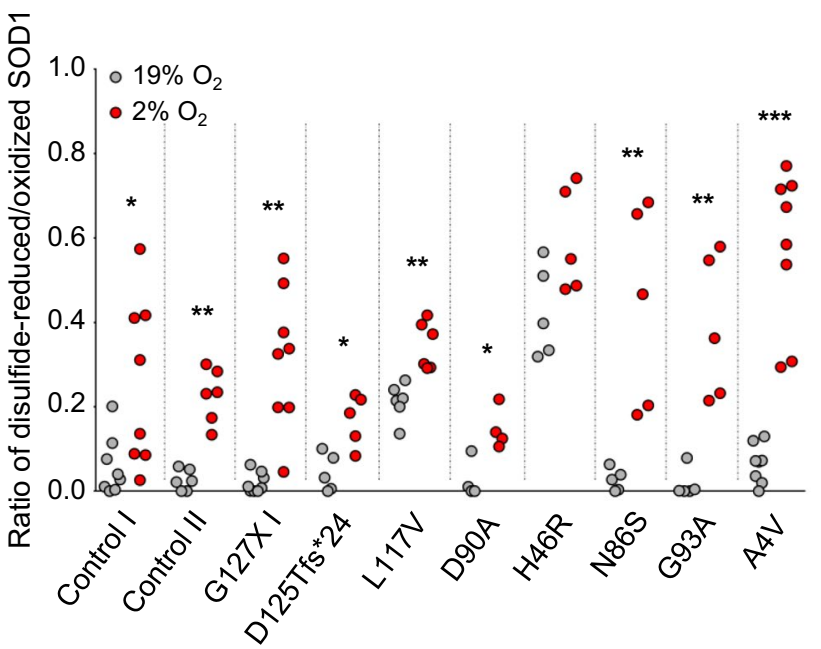

C

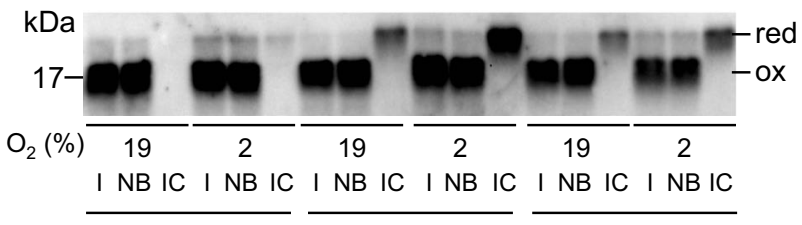

Control I

G93A

A4V

Fig. 5 Low $\mathrm{O}_{2}$ tension promotes disulfide bond reduction and disorder of SOD1. Analysis of MNAC extracts following exposure to $19 \%$ or $2 \% \mathrm{O}_{2}$ for $24 \mathrm{~h}$. a Non-reducing SDS-PAGE followed by western blotting with an anti-SOD1 aa 24-39 antibody was used to resolve disulfide-reduced (red) and -oxidized (ox) SOD1. b Scatter plot showing the ratios of disulfide-reduced to -oxidized SOD1 at $19 \%$ (grey circles) versus $2 \%$ (red circles) $\mathrm{O}_{2}$. Data are expressed as the mean $\pm \mathrm{SD}$ of four to eight technical replicates from two to six independent differentiations, $* p<0.05, * * p<0.01, * * * p<0.001$, analyzed by Mann-Whitney $\mathrm{U}$ test comparing $19 \%$ versus $2 \% \mathrm{O}_{2}$. c Western blot showing analysis of immunocaptured disordered SOD1. Input (I, 1/40th of the sample), non-bound (NB, 1/40th) and immunocaptured (IC, entire sample) fractions of SOD1 from MNACs cultured at either $19 \% \mathrm{O}_{2}$, or $2 \% \mathrm{O}_{2}$, for $24 \mathrm{~h}$. ICs were performed using a rabbit anti-SOD1 aa 24-39 antibody immobilized on Dynabeads. Disulfide-reduced and -oxidized SOD1 were quantified using a rabbit anti-SOD1 aa 57-72 antibody. Only disulfide-reduced SOD1 was captured

mutant SOD1s. However, this was not the case for the SOD $1^{\mathrm{H} 46 \mathrm{R}}$ line, where a large proportion of the mutant protein is known to be disulfide-reduced under control conditions [75]. 
Fig. 6 Low $\mathrm{O}_{2}$ tension does not alter known determinants of SOD1 C57-C146 redox status. Quantification of: a CCS or b glutaredoxin-1 in MNAC extracts by western blotting (Supplementary Fig. 7b), normalized to $\beta$-actin as a loading control. Cells were exposed to $19 \%$ $\mathrm{O}_{2}$ (grey bars) or $2 \% \mathrm{O}_{2}$ (red bars) for $24 \mathrm{~h}$. Data were plotted as a ratio of the level present in replicate cultures maintained at $19 \% \mathrm{O}_{2}$ for $24 \mathrm{~h}$ and expressed as the mean $\pm \mathrm{SD}$ of four to ten technical replicates from two to six independent differentiations, analyzed by Mann-Whitney U test. c GSH levels, d GSSG levels and e GSH/ GSSG ratios determined in MNACs (left, red bars) and fibroblasts (right, blue bars). Data are expressed as the mean \pm SD of six technical replicates from two independent differentiations for MNACs and of three technical replicates from one experiment for fibroblasts, ${ }^{*} p<0.05$, analyzed by Mann-Whitney U test comparing $19 \%$ versus $2 \% \mathrm{O}_{2}$ for MNACs

\section{Disordered SOD1 in MNACs lacks the disulfide bond}

To confirm that disordered SOD1 lacks the C57-C146 disulfide bond, we immunocaptured SOD1 from extracts of MNACs, which had been cultured at $19 \%$ or $2 \% \mathrm{O}_{2}$, using the same antibody (SOD1 aa 24-39) and capture conditions $\left(1 \mathrm{~h}\right.$ at $\left.23{ }^{\circ} \mathrm{C}\right)$ used in the misELISA. This antibody reacts with disordered SOD1, independent of the C57-C146 disulfide status [33]. Disulfide-reduced and -oxidized SOD1 were quantified by non-reduced western blotting (Fig. 5c). Input samples from control, SOD $1^{\mathrm{G} 93 \mathrm{~A}}$ and $\mathrm{SOD} 1^{\mathrm{A} 4 \mathrm{~V}}$ MNACs contained a majority of oxidized and a small proportion of reduced SOD1, which increased under low $\mathrm{O}_{2}$ conditions. Notably, an antibody specific for disordered SOD1 captured only disulfide-reduced SOD1. In control MNACs, disordered SOD1 was not detected at $19 \% \mathrm{O}_{2}$ but increased at $2 \% \mathrm{O}_{2}$ to $\sim 1.4 \%$ of the disulfide-reduced SOD1 in the input sample. In SOD $1^{\mathrm{G} 93 \mathrm{~A}}$ and SOD $1^{\mathrm{A} 4 \mathrm{~V}}$ MNACs, disordered, disulfide-reduced SOD1 increased substantially (to $21 \%$ and $10 \%$ of the input samples at $2 \% \mathrm{O}_{2}$, respectively). Hence, even in MNACs carrying mutant SOD1s, the majority of disulfide-reduced SOD1 retained an ordered structure. This agrees with observations in the spinal cord of SOD1 $\mathrm{Tg}$ mouse models, where approximately $5-10 \%$ of disulfide-reduced human SOD1 is disordered [77, 78].

\section{Low oxygen tension does not alter other determinants of SOD1 redox status}

The main mechanism for oxidation of the C57-C146 disulfide bond involves catalysis by CCS and is dependent on $\mathrm{O}_{2}[26,30,36]$. The bond can be reduced by a mechanism involving reducing equivalents from $\mathrm{GSH}$ via glutaredoxin-1 [19]. To determine whether levels of CCS or glutaredoxin-1 were affected by low $\mathrm{O}_{2}$ tension and thus responsible for increased disordered SOD1, we analyzed their levels in MNACs grown at 19\% versus 2\% $\mathrm{O}_{2}$. However, no significant changes were detected in CCS or glutaredoxin-1 levels by western blotting (Fig. 6a and
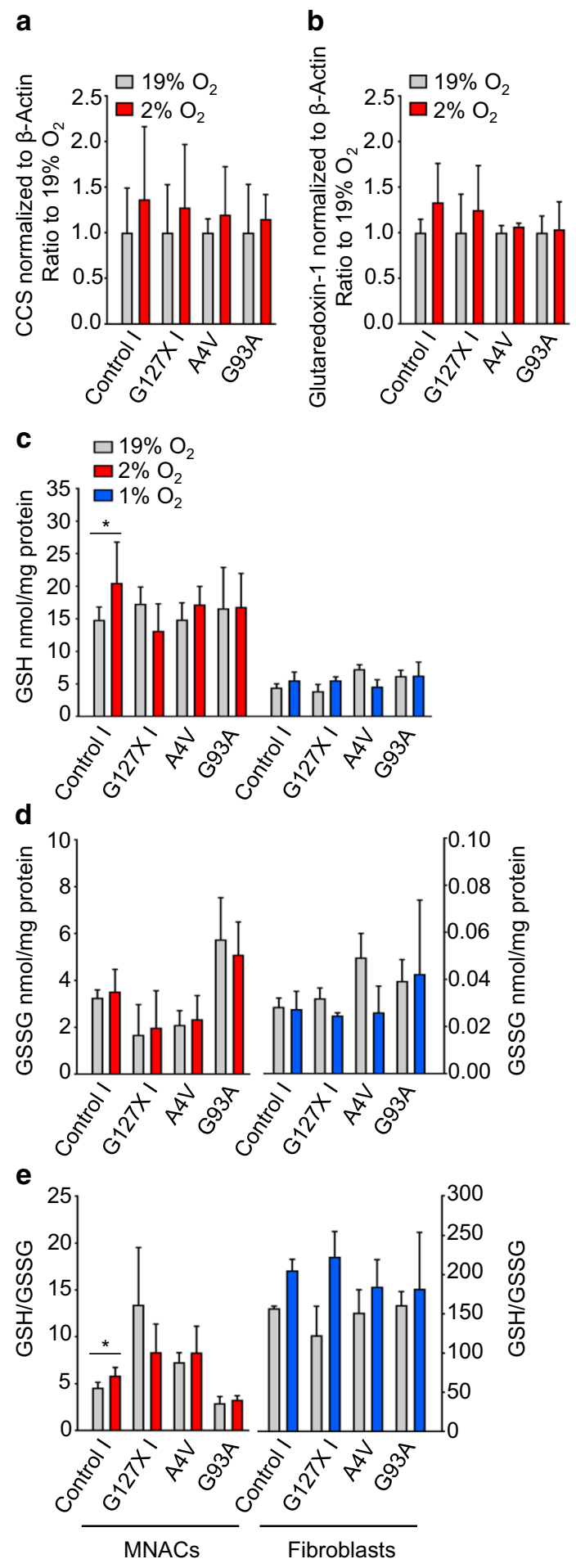

b and Supplementary Fig. 7). Next, we quantified GSH and GSSG, which form the principal redox couple in the cytosol. GSH and GSSG concentrations were higher in MNACs than in fibroblasts, but exposure to low $\mathrm{O}_{2}$ tension did not lead to significant changes in the levels of GSH (Fig. 6c) or GSSG (Fig. 6d). The concentrations of GSSG were remarkably high in MNACs, resulting in very 
low GSH/GSSG ratios, but these were not affected by $\mathrm{O}_{2}$ tension (Fig. 6e). Hence, low $\mathrm{O}_{2}$ tensions do not induce disordered, disulfide-reduced SOD1 via gross perturbation of the GSH/GSSG redox couple [69].

\section{Maintenance of the disulfide bond and SOD1 structure is oxygen dependent}

Increase in disordered SOD1 at low $\mathrm{O}_{2}$ tension could be due to impaired disulfide oxidation of newly synthesized SOD1, or to the reduction of the disulfide bond in the mature protein. To distinguish the relative contribution of these two possible mechanisms, we compared the response in disordered SOD1 in fibroblasts cultured in the absence or presence of the protein synthesis inhibitor CHX for $24 \mathrm{~h}$. No significant effects were seen on the expression of SOD1 relative to total protein following CHX treatment (Supplementary Fig. 8). Inhibition of protein synthesis led to a small increase in the level of disordered SOD $1^{\mathrm{WT}}$ in the control fibroblasts cultured at 19\% (Fig. 7a). This suggests that CHX treatment had a slight effect on the capacity of the cells to handle disordered SOD1. However, it did not suppress the increase in disordered SOD $1^{\text {WT }}$ in control fibroblasts at $1 \% \mathrm{O}_{2}$. CHX also resulted in a striking reduction in disordered SOD1 in the SOD $1^{\mathrm{G} 127 \mathrm{X}}$ line at both $\mathrm{O}_{2}$ tensions (Fig. 7b). This confirmed that the inhibition of protein synthesis was efficient. It also showed that $\mathrm{CHX}$ treatment did not significantly affect the degradation of the disordered mutant protein. In the $\mathrm{SOD} 1^{\mathrm{G} 93 \mathrm{~A}}$ line, $\mathrm{CHX}$ treatment resulted in a reduction in disordered SOD1 at both $\mathrm{O}_{2}$ tensions (Fig. 7c). Hence,

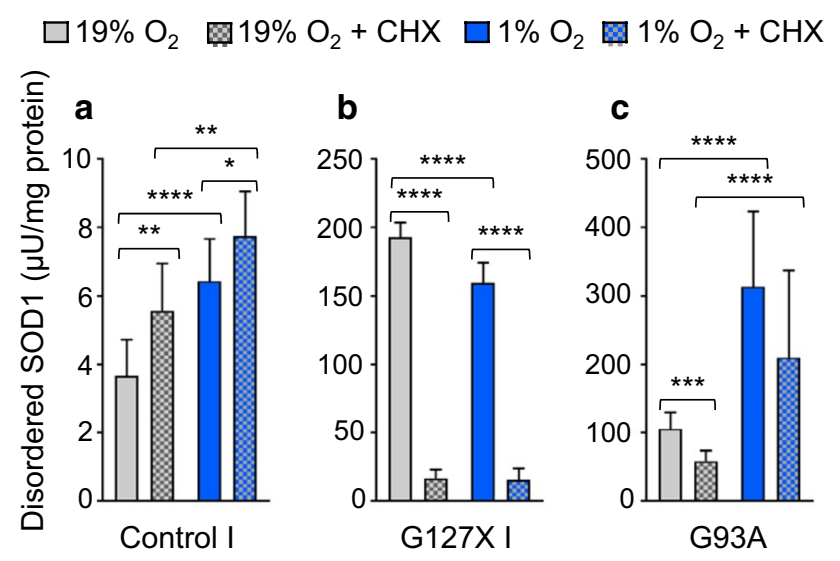

Fig. 7 Low $\mathrm{O}_{2}$ tension increases disorder in both nascent and mature SOD1. Disordered SOD1 was quantified in fibroblast extracts by misELISA and normalized to total protein; a Control I, b SOD1 ${ }^{\mathrm{G} 127 \mathrm{X}}$ and $\mathbf{c}$ SOD $1^{\mathrm{G} 93 \mathrm{~A}}$. Cells were grown at $19 \% \mathrm{O}_{2}$ (grey bars) or $1 \% \mathrm{O}_{2}$ (blue bars) for $24 \mathrm{~h}$ in the absence, or presence (checkerboard pattern) of cycloheximide (CHX; $50 \mu \mathrm{g} / \mathrm{ml}$ ). Data are expressed as the mean $\pm \mathrm{SD}$ of nine technical replicates from three independent experiments, ${ }^{*} p<0.05, * * p<0.01, * * * * p<0.0001$, analyzed by MannWhitney U test a proportion of disordered SOD1 resulted from a lack of disulfide oxidation in newly synthesized SOD $1{ }^{\mathrm{G} 93 \mathrm{~A}}$. However, the response in disordered SOD1 was still greatly enhanced at $1 \%$ compared to $19 \% \mathrm{O}_{2}$ when protein synthesis was inhibited. Thus, $\mathrm{O}_{2}$ is also required for maintenance of the disulfide bond and structure of the existing pool of mature SOD1.

\section{Low oxygen tension promotes SOD1 aggregation}

Since disulfide reduction and disorder promote SOD1 aggregation $[21,35,53]$, we quantified the amount of SOD1 in detergent-resistant aggregates by western blotting. To identify the optimal antibody for this purpose, we compared antibodies to epitopes in the N-terminus (aa 24-39), the central region (aa 57-72) and the C-terminus (aa 144-153). A large number of apparently non-specific cross-reacting bands of unknown identities were evident (Supplementary Fig. 9). Since these bands differed between antibodies, we only quantified full-length SOD1 co-migrating with the SOD1 standard used for quantification. All three antibodies detected this band similarly. However, we used the aa 57-72 antibody because it was the most sensitive. For SOD $1^{\mathrm{G} 127 \mathrm{X}}$ quantification, we used the aa 123-127 GQRWK antibody, which is specific for this mutant.

Low levels of aggregation were found in fibroblasts, which did not increase significantly in response to low $\mathrm{O}_{2}$ (Fig. 8). In contrast, we found that low $\mathrm{O}_{2}$ tension induced marked increases in aggregation in MNACs carrying fulllength mutant SOD1s (E78_R79insSI, N86S, G93A and A4V), but not in SOD1 ${ }^{\text {WT }}$ control lines or SOD $1^{\mathrm{L} 117 \mathrm{~V}}$, which has SOD $1^{\mathrm{WT}}$-like stability [71]. The $S O D 1^{H 46 R}$ mutation disrupts copper binding catalyzed via CCS and impairs formation of the disulfide bond [75]. In agreement, the high level of aggregation present at $19 \% \mathrm{O}_{2}$ in the SOD $1^{\mathrm{H} 46 \mathrm{R}}$ line did not change at $2 \% \mathrm{O}_{2}$. Neither of the lines expressing the $\mathrm{C}$-terminally truncated mutants that lack the disulfide bond $\left(\mathrm{SOD} 1^{\mathrm{G} 127 \mathrm{X}}\right.$ and SOD1 $1^{\mathrm{D} 125 \mathrm{Tf} * 24}$ ), showed increased aggregation. Hence, increased aggregation correlated closely with increased disorder in MNACs expressing full-length mutant SOD1s.

\section{Discussion}

By comparing the responses of a large panel of patientderived cell lines carrying genetically and biochemically distinct SOD1 variants, we have found that low $\mathrm{O}_{2}$ tension leads to remarkably large increases in SOD1 C57-C146 disulfide bond reduction and disorder. In addition to being required for bond formation, we have identified that $\mathrm{O}_{2}$ is also critical for its maintenance. Furthermore, low $\mathrm{O}_{2}$ 


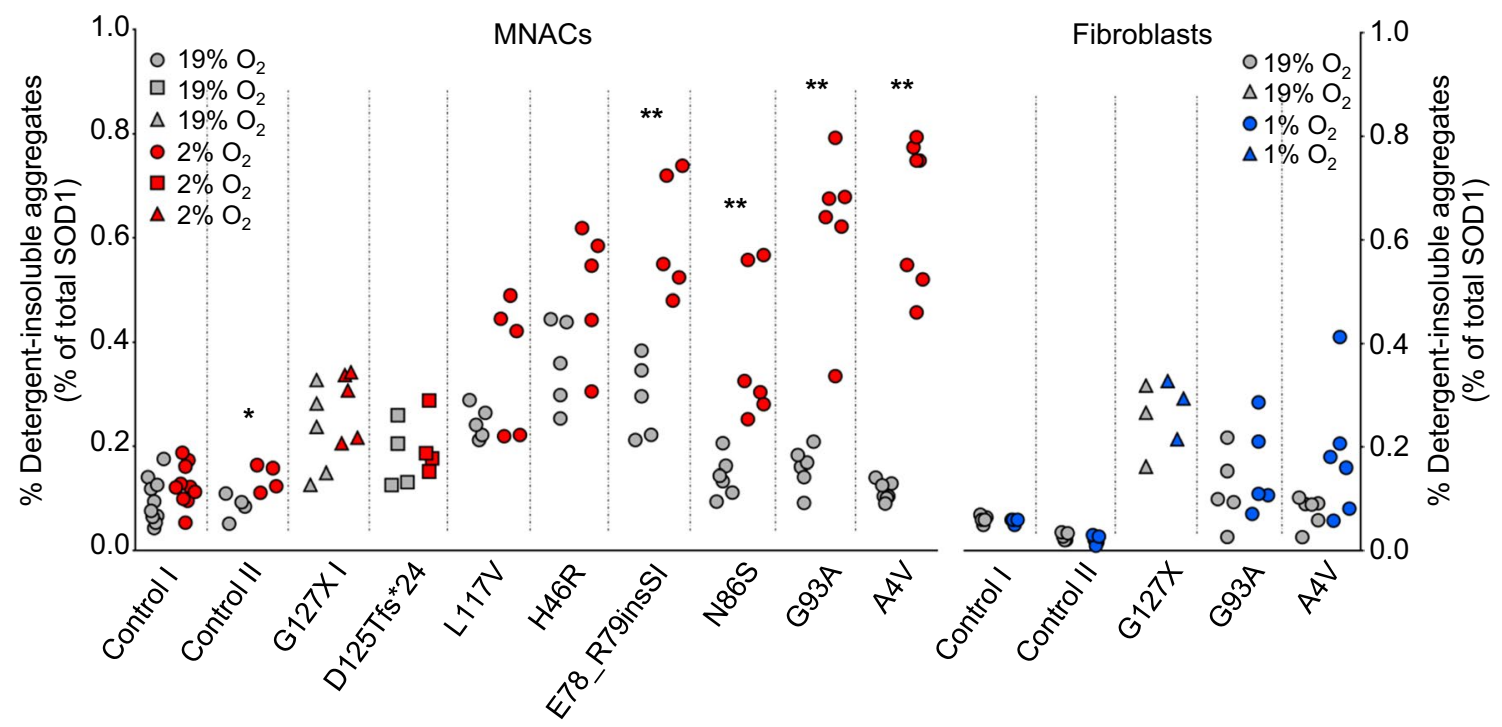

Fig. 8 Low $\mathrm{O}_{2}$ tension promotes SOD1 aggregation in MNACs but not in fibroblasts. Scatter plots show the amounts of SOD1 present in the detergent-insoluble fraction determined by western blotting as a $\%$ of soluble SOD1 present in the cell extract determined by total SOD1 ELISA: MNACs (red; $2 \% \mathrm{O}_{2}$ for $24 \mathrm{~h}$ ) and fibroblasts (blue; $1 \% \mathrm{O}_{2}$ for $24 \mathrm{~h}$ ) in comparison to replicate cultures (grey; $19 \% \mathrm{O}_{2}$ for $24 \mathrm{~h})$. Full-length SOD1s are depicted as filled circles and quantified using an anti-SOD1 (aa 57-72) antibody (Supplementary Figs. 10a and $11 \mathrm{a}$ ). The SOD $1^{\mathrm{G} 127 \mathrm{X}}$ mutant protein (filled triangles) was quantified using a hSOD1 ${ }^{\mathrm{G} 127 \mathrm{X}}$-specific antibody (Supplementary Figs. 10b and $11 \mathrm{~b}$ ). The SOD1 ${ }^{\mathrm{D} 125 \mathrm{Tfs} * 24}$ mutant protein (filled squares) was

tension resulted in enhanced mutant SOD1 aggregation in MNACs but not in fibroblasts. This supports the idea that in human patient-derived models, as well as in Tg mice, the C57-C146 disulfide bond is an ALS-related Achilles heel of SOD1 in the reducing environment of the cytosol.

The $\mathrm{O}_{2}$ tensions found to enhance disordered SOD1 are within the range considered to be normoxic in human and animal tissues. However, the range of $\mathrm{O}_{2}$ tensions present within cultured cells is likely to be lower. This is due to both the rate of $\mathrm{O}_{2}$ diffusion through the culture medium and the rate of $\mathrm{O}_{2}$ consumption by cellular respiration, which depends on both cellular mass and the rate of oxidative metabolism [61]. Because these variables are difficult to control for between different cell lines, we chose to compare replicate samples cultured at different $\mathrm{O}_{2}$ tensions. The cells, which had been propagated and adapted to growth at $19 \%$ $\mathrm{O}_{2}$, were tested within a range that was found not to cause overt toxicity. A study in young resting awake mice found that $\mathrm{O}_{2}$ tensions in the CNS vary between 0.2 and 5\% [55]. Even lower levels were recorded under normal conditions, e.g. in periarteriolar areas. Considering this great variation found in young mice, it is reasonable to assume that localized hypoxia could occur transiently, or more chronically, in middle-aged or elderly humans even in the absence of overt disease. quantified using the aa 57-72 antibody (Supplementary Figs. 10a and 11a). The identity of the mutant protein band was confirmed by lack of reactivity against a C-terminal SOD1 (aa 143-153) peptide (Supplementary Fig. 11c). Data are expressed as the mean \pm SD of four to ten technical replicates from two to six independent MNACs differentiations, and of five to six technical replicates from two to three independent experiments for fibroblasts, with the exception of the SOD1 ${ }^{\mathrm{G} 127 \mathrm{X}}$ fibroblast line where data are expressed as the mean \pm SD of three technical replicates from one experiment; ${ }^{*} p<0.05$, $* * p<0.01$, analyzed by Mann-Whitney U test

In SOD1 ALS mouse models, the average lifespan of homozygous $\mathrm{Tg}$ mice is approximately half that of hemizygous animals $[44,45]$. In human ALS there is also a dosedependence on mutant SOD1; doubling of the load of mutant SOD1 in individuals homozygous for SOD1 mutations L84F, N86S or L126S results in earlier onset and more rapid progression than in the heterozygous state $[1,16,42$, 49]. Furthermore, the D $90 A$ mutant protein, which has wildtype-like stability, typically only causes ALS in homozygous individuals [5]. Therefore, if our results showing large increases in disordered SOD1 in MNACs in response to low $\mathrm{O}_{2}$ tensions translate to the human CNS, this could likely contribute to the initiation and progression of ALS.

Recent findings in vivo suggest that prion-like growth and spread of SOD1 aggregation could be the primary disease mechanism of SOD1-induced ALS [7, 8, 12, 28]. Disordered SOD1 species are critical substrates for both the nucleation and growth of aggregates [21, 22, 35, 51, 53]. Typically, in animal or cell models of ALS, SOD1 overexpression is required for substantial aggregation to occur [63]. Our results show that in patient-derived MNACs that do not overexpress SOD1, even a short ( $24 \mathrm{~h})$ exposure to low $\mathrm{O}_{2}$ tension can induce large increases in mutant SOD1 aggregation. This suggests that in patients SOD1 aggregation would 
have a greater probability of initiation in areas of the CNS with sustained low $\mathrm{O}_{2}$ tension.

As to the impact of low $\mathrm{O}_{2}$ tension on animal models, van den Bosch et al. [73] found no effect on the lifespan of hSOD1 ${ }^{\mathrm{G} 93 \mathrm{~A}}$ Gur Tg mice exposed to $10 \% \mathrm{O}_{2}$ at early or late symptomatic stages [73]. However, even when housed in normoxic conditions $\left(21 \% \mathrm{O}_{2}\right)$, a significant proportion of mutant SOD1 in the spinal cord of hSOD $1^{\mathrm{G} 93 \mathrm{~A}}$ mice is disulfide-reduced due to the extreme level of overexpression in this line [46]. Moreover, exponential aggregation of hSOD ${ }^{\mathrm{G} 93 \mathrm{~A}}$ begins even before birth and has advanced considerably by the stages that mice were exposed to low $\mathrm{O}_{2}$ in the van den Bosch study [11]. Hence, it is unlikely that the effects that we have found in human patient-derived models in this study would be detectable in the hSOD $1^{\mathrm{G} 93 \mathrm{~A}}$ Tg model.

Significant increases in disulfide-reduced and disordered SOD1 were also seen in cells from healthy control individuals and cells derived from patients carrying ALSlinked mutations in other genes. Although we only detected a significant increase in the aggregation of mutant and not SOD ${ }^{\text {WT }}$ over this short period, this could be important given the mounting evidence for the involvement of SOD $1^{\text {WT }}$ in ALS.

In summary, we show that $\mathrm{O}_{2}$ tension is a principal determinant of SOD1 disorder and aggregation. Our findings suggest that CNS areas with low $\mathrm{O}_{2}$ tension could act as foci for the initiation or progression of ALS. This mechanism might contribute to the enhanced risk for the disease associated with aging, as well as other factors that impair vascular perfusion.

Acknowledgements We thank the many individuals that generously provided patient or control samples. We thank Anna Wuolikainen for expert statistical advice and Agneta Öberg, Eva Jonsson, Eva Bern, Helena Alstermark, Matthew Marklund and Chloe Williams for skillful technical assistance. Swedish Metabolomics Centre, Umeå, Sweden (www.swedishmetabolomicscentre.se) is acknowledged for the measurement of GSH/GSSG by LC-MS.

Funding This work was supported by funding from the Swedish Research Council (VRMH 2015-02804), the Knut and Alice Wallenberg Foundation (2012.0091), the Bertil Hållsten Foundation, the Torsten Söderberg Foundation, the Swedish Brain Foundation (Hjärnfonden FO2015-0234), the Ulla-Carin Lindquist Foundation, NEURO Foundation, the Stratneuro Initiative, Västerbotten County Council, the Research Foundation for Clinical Neuroscience, Umeå University and the Kempe Foundations. MS was supported by the Else Kröner Fresenius Stiftung.

\section{Compliance with ethical standards}

Conflict of interest The authors declare that they have no conflict of interest.

Open Access This article is distributed under the terms of the Creative Commons Attribution 4.0 International License (http://creativeco mmons.org/licenses/by/4.0/), which permits unrestricted use, distribution, and reproduction in any medium, provided you give appropriate credit to the original author(s) and the source, provide a link to the Creative Commons license, and indicate if changes were made.

\section{References}

1. Alavi A, Nafissi S, Rohani M, Zamani B, Sedighi B, Shamshiri $\mathrm{H}$ et al (2013) Genetic analysis and SOD1 mutation screening in Iranian amyotrophic lateral sclerosis patients. Neurobiol Aging 34(1516):e1511-e1518. https://doi.org/10.1016/j.neurobiola ging.2012.09.006

2. Amoroso MW, Croft GF, Williams DJ, O'Keeffe S, Carrasco MA, Davis AR et al (2013) Accelerated high-yield generation of limbinnervating motor neurons from human stem cells. J Neurosci Off J Soc Neurosci 33:574-586. https://doi.org/10.1523/JNEUR OSCI.0906-12.2013

3. Andersen PM, Al-Chalabi A (2011) Clinical genetics of amyotrophic lateral sclerosis: what do we really know? Nat Rev Neurol 7:603-615. https://doi.org/10.1038/nrneurol.2011.150

4. Andersen PM, Borasio GD, Dengler R, Hardiman O, Kollewe K, Leigh PN et al (2005) EFNS task force on management of amyotrophic lateral sclerosis: guidelines for diagnosing and clinical care of patients and relatives. Eur J Neurol Off J Eur Fed Neurol Soc 12:921-938. https://doi.org/10.1111/j.1468-1331.2005.01351 . $\mathrm{X}$

5. Andersen PM, Forsgren L, Binzer M, Nilsson P, Ala-Hurula V, Keranen ML et al (1996) Autosomal recessive adult-onset amyotrophic lateral sclerosis associated with homozygosity for Asp90Ala CuZn-superoxide dismutase mutation. A clinical and genealogical study of 36 patients. Brain J Neurol 119(Pt 4):1153-1172

6. Andersen PM, Nilsson P, Ala-Hurula V, Keränen ML, Tarvainen I, Haltia T et al (1995) Amyotrophic lateral sclerosis associated with homozygosity for an Asp90Ala mutation in $\mathrm{CuZn}$-superoxide dismutase. Nat Genet 10:61-66. https://doi.org/10.1038/ng0595-61

7. Ayers JI, Fromholt S, Koch M, DeBosier A, McMahon B, Xu $\mathrm{G}$ et al (2014) Experimental transmissibility of mutant SOD1 motor neuron disease. Acta Neuropathol 128:791-803. https:// doi.org/10.1007/s00401-014-1342-7

8. Ayers JI, Fromholt SE, O'Neal VM, Diamond JH, Borchelt DR (2016) Prion-like propagation of mutant SOD1 misfolding and motor neuron disease spread along neuroanatomical pathways. Acta Neuropathol 131:103-114. https://doi.org/10.1007/s0040 1-015-1514-0

9. Ayers JI, Xu G, Pletnikova O, Troncoso JC, Hart PJ, Borchelt DR (2014) Conformational specificity of the C4F6 SOD1 antibody; low frequency of reactivity in sporadic ALS cases. Acta Neuropathol Commun 2:55. https://doi.org/10.1186/2051-5960-2-55

10. Bergemalm D, Forsberg K, Srivastava V, Graffmo KS, Andersen PM, Brannstrom T et al (2010) Superoxide dismutase- 1 and other proteins in inclusions from transgenic amyotrophic lateral sclerosis model mice. J Neurochem 114:408-418. https://doi.org/10.11 $11 / j .1471-4159.2010 .06753 . x$

11. Bergh J, Zetterström P, Andersen PM, Brännström T, Graffmo KS, Jonsson PA et al (2015) Structural and kinetic analysis of protein-aggregate strains in vivo using binary epitope mapping. Proc Natl Acad Sci USA 112:4489-4494. https://doi.org/10.1073/ pnas. 1419228112

12. Bidhendi EE, Bergh J, Zetterstrom P, Andersen PM, Marklund SL, Brannstrom T (2016) Two superoxide dismutase prion strains transmit amyotrophic lateral sclerosis-like disease. J Clin Invest 126:2249-2253. https://doi.org/10.1172/JCI84360 
13. Birve A, Neuwirth C, Weber M, Marklund SL, Nilsson AC, Jonsson PA et al (2010) A novel SOD1 splice site mutation associated with familial ALS revealed by SOD activity analysis. Hum Mol Genet 19:4201-4206. https://doi.org/10.1093/hmg/ddq338

14. Bordo D, Djinovic K, Bolognesi M (1994) Conserved patterns in the $\mathrm{Cu}, \mathrm{Zn}$ superoxide dismutase family. J Mol Biol 238:366-386. https://doi.org/10.1006/jmbi.1994.1298

15. Bosco DA, Morfini G, Karabacak NM, Song Y, Gros-Louis F, Pasinelli P et al (2010) Wild-type and mutant SOD1 share an aberrant conformation and a common pathogenic pathway in ALS. Nat Neurosci 13:1396-1403. https://doi.org/10.1038/nn.2660

16. Boukaftane Y, Khoris J, Moulard B, Salachas F, Meininger V, Malafosse A et al (1998) Identification of six novel SOD1 gene mutations in familial amyotrophic lateral sclerosis. Can J Neurol Sci 25:192-196

17. Brotherton TE, Li Y, Cooper D, Gearing M, Julien JP, Rothstein JD et al (2012) Localization of a toxic form of superoxide dismutase 1 protein to pathologically affected tissues in familial ALS. Proc Natl Acad Sci USA 109:5505-5510. https://doi. org/10.1073/pnas.1115009109

18. Cao L, Waldon D, Teffera Y, Roberts J, Wells M, Langley M et al (2013) Ratios of biliary glutathione disulfide (GSSG) to glutathione $(\mathrm{GSH})$ : a potential index to screen drug-induced hepatic oxidative stress in rats and mice. Anal Bioanal Chem 405:2635-2642. https://doi.org/10.1007/s00216-012-6661-8

19. Carroll MC, Outten CE, Proescher JB, Rosenfeld L, Watson WH, Whitson LJ et al (2006) The effects of glutaredoxin and copper activation pathways on the disulfide and stability of $\mathrm{Cu}$, Zn superoxide dismutase. J Biol Chem 281:28648-28656. https ://doi.org/10.1074/jbc.m600138200

20. Charcot JM (1873) Lecons sur les maladies du système nervaux. 2nd series, collected by Bourneville. Charcot, J.M. (1881) Lectures on the diseases of the nervous system, vol 2, series 2, Sigersen G (trans and ed). London: New Sydenham Society, pp 163-204

21. Chattopadhyay M, Durazo A, Sohn SH, Strong CD, Gralla EB, Whitelegge JP et al (2008) Initiation and elongation in fibrillation of ALS-linked superoxide dismutase. Proc Natl Acad Sci USA 105:18663-18668. https://doi.org/10.1073/pnas.08070 58105

22. Chattopadhyay M, Nwadibia E, Strong CD, Gralla EB, Valentine JS, Whitelegge JP (2015) The disulfide bond, but not zinc or dimerization, controls initiation and seeded growth in amyotrophic lateral sclerosis-linked $\mathrm{Cu}, \mathrm{Zn}$ superoxide dismutase (SOD1) fibrillation. J Biol Chem 290:30624-30636. https://doi. org/10.1074/jbc.M115.666503

23. Chio A, Benzi G, Dossena M, Mutani R, Mora G (2005) Severely increased risk of amyotrophic lateral sclerosis among Italian professional football players. Brain J Neurol 128:472-476. https:// doi.org/10.1093/brain/awh373

24. Chondrogianni M, Bregianni M, Frantzeskaki F, GiamarellosBourboulis E, Anagnostou E, Kararizou E et al (2018) Three new case reports of arteriovenous malformation-related amyotrophic lateral sclerosis. J Neurol Sci 393:58-62. https://doi.org/10.1016/j. jns.2018.08.011

25. Claeson A-S, Gouveia-Figueira S, Stenlund H, Johansson AI (2019) A standardized protocol for comparable analysis of GSH/ GSSG by UHPLC-ESI-MSMS for human plasma. J Chromatogr B Analyt Technol Biomed Life Sci 1104:67-72

26. Culotta VC, Klomp LW, Strain J, Casareno RL, Krems B, Gitlin JD (1997) The copper chaperone for superoxide dismutase. J Biol Chem 272:23469-23472

27. Da Cruz S, Bui A, Saberi S, Lee SK, Stauffer J, McAlonisDownes M et al (2017) Misfolded SOD1 is not a primary component of sporadic ALS. Acta Neuropathol 134:97-111. https://doi. org/10.1007/s00401-017-1688-8
28. Ekhtiari Bidhendi E, Bergh J, Zetterström P, Forsberg K, Pakkenberg B, Andersen PM et al (2018) Mutant superoxide dismutase aggregates from human spinal cord transmit amyotrophic lateral sclerosis. Acta Neuropathol. https://doi.org/10.1007/s0040 1-018-1915-y

29. Erecinska M, Silver IA (2001) Tissue oxygen tension and brain sensitivity to hypoxia. Respir Physiol 128:263-276

30. Fetherolf MM, Boyd SD, Taylor AB, Kim HJ, Wohlschlegel JA, Blackburn NJ et al (2017) Copper-zinc superoxide dismutase is activated through a sulfenic acid intermediate at a copper-ion entry site. J Biol Chem. https://doi.org/10.1074/jbc.m117.775981

31. Forsberg K, Andersen PM, Marklund SL, Brännström T (2011) Glial nuclear aggregates of superoxide dismutase-1 are regularly present in patients with amyotrophic lateral sclerosis. Acta Neuropathol 121:623-634. https://doi.org/10.1007/s00401-011-0805-3

32. Forsberg K, Graffmo K, Pakkenberg B, Weber M, Wirenfeldt M, Marklund SL, Brännström T, Andersen PM (2019) Misfolded SOD1 inclusions in patients with mutations in $C 9$ orf 72 and other ALS/FTD-associated genes. J Neurol Neurosurg Psychiatry (in press)

33. Forsberg K, Jonsson PA, Andersen PM, Bergemalm D, Graffmo KS, Hultdin M et al (2010) Novel antibodies reveal inclusions containing non-native SOD1 in sporadic ALS patients. PLoS ONE 5:e11552. https://doi.org/10.1371/journal.pone.0011552

34. Freischmidt A, Wieland T, Richter B, Ruf W, Schaeffer V, Muller $K$ et al (2015) Haploinsufficiency of TBK1 causes familial ALS and fronto-temporal dementia. Nat Neurosci 18:631-636. https:// doi.org/10.1038/nn.4000

35. Furukawa Y, Kaneko K, Yamanaka K, O'Halloran TV, Nukina $\mathrm{N}$ (2008) Complete loss of post-translational modifications triggers fibrillar aggregation of SOD1 in the familial form of amyotrophic lateral sclerosis. J Biol Chem 283:24167-24176. https:// doi.org/10.1074/jbc.M802083200

36. Furukawa Y, Torres AS, O'Halloran TV (2004) Oxygen-induced maturation of SOD1: a key role for disulfide formation by the copper chaperone CCS. EMBO J 23:2872-2881. https://doi. org/10.1038/sj.emboj.7600276

37. Gallo V, Bueno-De-Mesquita HB, Vermeulen R, Andersen PM, Kyrozis A, Linseisen J et al (2009) Smoking and risk for amyotrophic lateral sclerosis: analysis of the EPIC cohort. Ann Neurol 65:378-385. https://doi.org/10.1002/ana.21653

38. Gallo V, Vanacore N, Bueno-de-Mesquita HB, Vermeulen R, Brayne C, Pearce N et al (2016) Physical activity and risk of Amyotrophic Lateral Sclerosis in a prospective cohort study. Eur J Epidemiol 31:255-266. https://doi.org/10.1007/s1065 4-016-0119-9

39. Grad LI, Yerbury JJ, Turner BJ, Guest WC, Pokrishevsky E, O'Neill MA et al (2014) Intercellular propagated misfolding of wild-type $\mathrm{Cu} / \mathrm{Zn}$ superoxide dismutase occurs via exosomedependent and -independent mechanisms. Proc Natl Acad Sci USA 111:3620-3625. https://doi.org/10.1073/pnas.1312245111

40. Graffmo KS, Forsberg K, Bergh J, Birve A, Zetterstrom P, Andersen PM et al (2013) Expression of wild-type human superoxide dismutase-1 in mice causes amyotrophic lateral sclerosis. Hum Mol Genet 22:51-60. https://doi.org/10.1093/hmg/dds399

41. Haidet-Phillips AM, Hester ME, Miranda CJ, Meyer K, Braun L, Frakes A et al (2011) Astrocytes from familial and sporadic ALS patients are toxic to motor neurons. Nat Biotechnol 29:824-828

42. Hayward C, Brock DJ, Minns RA, Swingler RJ (1998) Homozygosity for Asn86Ser mutation in the CuZn-superoxide dismutase gene produces a severe clinical phenotype in a juvenile onset case of familial amyotrophic lateral sclerosis. J Med Genet 35:174

43. Iadecola $C$ (2017) The neurovascular unit coming of age: a journey through neurovascular coupling in health and disease. Neuron 96:17-42. https://doi.org/10.1016/j.neuron.2017.07.030 
44. Jaarsma D, Haasdijk ED, Grashorn JA, Hawkins R, van Duijn $\mathrm{W}$, Verspaget $\mathrm{HW}$ et al (2000) Human $\mathrm{Cu} / \mathrm{Zn}$ superoxide dismutase (SOD1) overexpression in mice causes mitochondrial vacuolization, axonal degeneration, and premature motoneuron death and accelerates motoneuron disease in mice expressing a familial amyotrophic lateral sclerosis mutant SOD1. Neurobiol Dis 7:623-643. https://doi.org/10.1006/nbdi.2000.0299

45. Jonsson PA, Ernhill K, Andersen PM, Bergemalm D, Brännström $\mathrm{T}$, Gredal O et al (2004) Minute quantities of misfolded mutant superoxide dismutase-1 cause amyotrophic lateral sclerosis. Brain 127:73-88. https://doi.org/10.1093/brain/awh005

46. Jonsson PA, Graffmo KS, Andersen PM, Brännström T, Lindberg M, Oliveberg M et al (2006) Disulphide-reduced superoxide dismutase-1 in CNS of transgenic amyotrophic lateral sclerosis models. Brain 129:451-464. https://doi.org/10.1093/brain/awh704

47. Jonsson PA, Graffmo KS, Andersen PM, Marklund SL, Brannstrom $T$ (2009) Superoxide dismutase in amyotrophic lateral sclerosis patients homozygous for the D90A mutation. Neurobiol Dis 36:421424. https://doi.org/10.1016/j.nbd.2009.08.006

48. Karch CM, Prudencio M, Winkler DD, Hart PJ, Borchelt DR (2009) Role of mutant SOD1 disulfide oxidation and aggregation in the pathogenesis of familial ALS. Proc Natl Acad Sci USA 106:7774 7779. https://doi.org/10.1073/pnas.0902505106

49. Kato M, Aoki M, Ohta M, Nagai M, Ishizaki F, Nakamura S et al (2001) Marked reduction of the $\mathrm{Cu} / \mathrm{Zn}$ superoxide dismutase polypeptide in a case of familial amyotrophic lateral sclerosis with the homozygous mutation. Neurosci Lett 312:165-168

50. Keskin I, Birve A, Berdynski M, Hjertkvist K, Rofougaran R, Nilsson TK et al (2017) Comprehensive analysis to explain reduced or increased SOD1 enzymatic activity in ALS patients and their relatives. Amyotroph Lateral Scler Frontotemporal Degener 18:457463. https://doi.org/10.1080/21678421.2017.1301481

51. Keskin I, Forsgren E, Lange DJ, Weber M, Birve A, Synofzik M et al (2016) Effects of cellular pathway disturbances on misfolded superoxide dismutase-1 in fibroblasts derived from ALS patients. PLoS ONE 11:e0150133. https://doi.org/10.1371/journal.pone.0150133

52. Lamas NJ, Johnson-Kerner B, Roybon L, Kim YA, Garcia-Diaz A, Wichterle $\mathrm{H}$ et al (2014) Neurotrophic requirements of human motor neurons defined using amplified and purified stem cellderived cultures. PLoS ONE 9:e110324. https://doi.org/10.1371/ journal.pone.0110324

53. Lang L, Kurnik M, Danielsson J, Oliveberg M (2012) Fibrillation precursor of superoxide dismutase 1 revealed by gradual tuning of the protein-folding equilibrium. Proc Natl Acad Sci USA 109:17868-17873. https://doi.org/10.1073/pnas.1201795109

54. Linnebank M, McDougall CG, Krueger S, Biskup S, Neumann M, Weller M et al (2016) Novel cases of amyotrophic lateral sclerosis after treatment of cerebral arteriovenous malformationss. Swiss Med Wkly 146:w14361. https://doi.org/10.4414/smw.2016.14361

55. Lyons DG, Parpaleix A, Roche M, Charpak S (2016) Mapping oxygen concentration in the awake mouse brain. eLife. https://doi. org/10.7554/elife.12024

56. Maier M, Welt T, Wirth F, Montrasio F, Preisig D, McAfoose J et al (2018) A human-derived antibody targets misfolded SOD1 and ameliorates motor symptoms in mouse models of amyotrophic lateral sclerosis. Sci Transl Med. https://doi.org/10.1126/scitranslm ed.aah3924

57. Marklund SL, Andersen PM, Forsgren L, Nilsson P, Ohlsson PI, Wikander G et al (1997) Normal binding and reactivity of copper in mutant superoxide dismutase isolated from amyotrophic lateral sclerosis patients. J Neurochem 69:675-681

58. Miller AF (2012) Superoxide dismutases: ancient enzymes and new insights. FEBS Lett 586:585-595. https://doi.org/10.1016/j.febs1 et.2011.10.048

59. Okita K, Matsumura Y, Sato Y, Okada A, Morizane A, Okamoto $S$ et al (2011) A more efficient method to generate integration-free human iPS cells. Nat Methods 8:409-412. https://doi.org/10.1038/ nmeth.1591

60. Pare B, Lehmann M, Beaudin M, Nordstrom U, Saikali S, Julien JP et al (2018) Misfolded SOD1 pathology in sporadic amyotrophic lateral sclerosis. Sci Rep 8:14223. https://doi.org/10.1038/s4159 8-018-31773-Z

61. Pettersen EO, Larsen LH, Ramsing NB, Ebbesen P (2005) Pericellular oxygen depletion during ordinary tissue culturing, measured with oxygen microsensors. Cell Prolif 38:257-267. https://doi.org/ 10.1111/j.1365-2184.2005.00345.x

62. Pokrishevsky E, Grad LI, Yousefi M, Wang J, Mackenzie IR, Cashman NR (2012) Aberrant localization of FUS and TDP43 is associated with misfolding of SOD1 in amyotrophic lateral sclerosis. PLoS ONE 7:e35050. https://doi.org/10.1371/journal.pone.0035050

63. Prudencio M, Hart PJ, Borchelt DR, Andersen PM (2009) Variation in aggregation propensities among ALS-associated variants of SOD1: correlation to human disease. Hum Mol Genet 18:32173226. https://doi.org/10.1093/hmg/ddp260

64. Rodriguez JA, Shaw BF, Durazo A, Sohn SH, Doucette PA, Nersissian AM et al (2005) Destabilization of apoprotein is insufficient to explain $\mathrm{Cu}, \mathrm{Zn}$-superoxide dismutase-linked ALS pathogenesis. Proc Natl Acad Sci USA 102:10516-10521

65. Rosen DR, Siddique T, Patterson D, Figlewicz DA, Sapp P, Hentati A et al (1993) Mutations in $\mathrm{Cu} / \mathrm{Zn}$ superoxide dismutase gene are associated with familial amyotrophic lateral sclerosis. Nature 362:59-62. https://doi.org/10.1038/362059a0

66. Rosenbohm A, Kassubek J, Weydt P, Marroquin N, Volk AE, Kubisch $\mathrm{C}$ et al (2014) Can lesions to the motor cortex induce amyotrophic lateral sclerosis? J Neurol 261:283-290. https://doi. org/10.1007/s00415-013-7185-7

67. Santamaria N, Alhothali M, Alfonso MH, Breydo L, Uversky VN (2016) Intrinsic disorder in proteins involved in amyotrophic lateral sclerosis. Cell Mol Life Sci. https://doi.org/10.1007/s0001 8-016-2416-6

68. Sato T, Nakanishi T, Yamamoto Y, Andersen PM, Ogawa Y, Fukada $\mathrm{K}$ et al (2005) Rapid disease progression correlates with instability of mutant SOD1 in familial ALS. Neurology 65:1954-1957. https ://doi.org/10.1212/01.wnl.0000188760.53922.05

69. Schwarzlander M, Dick TP, Meyer AJ, Morgan B (2016) Dissecting redox biology using fluorescent protein sensors. Antioxid Redox Signal 24:680-712. https://doi.org/10.1089/ars.2015.6266

70. Sekhar A, Rumfeldt JA, Broom HR, Doyle CM, Sobering RE, Meiering EM et al (2016) Probing the free energy landscapes of ALS disease mutants of SOD1 by NMR spectroscopy. Proc Natl Acad Sci USA. https://doi.org/10.1073/pnas.1611418113

71. Synofzik M, Ronchi D, Keskin I, Basak AN, Wilhelm C, Gobbi C et al (2012) Mutant superoxide dismutase-1 indistinguishable from wild-type causes ALS. Hum Mol Genet 21:3568-3574. https://doi. org $/ 10.1093 / \mathrm{hmg} / \mathrm{dds} 188$

72. Turner MR, Goldacre R, Talbot K, Goldacre MJ (2016) Cerebrovascular injury as a risk factor for amyotrophic lateral sclerosis. J Neurol Neurosurg Psychiatry 87:244-246. https://doi.org/10.1136/ jnnp-2015-311157

73. Van Den Bosch L, Storkebaum E, Vleminckx V, Moons L, Vanopdenbosch L, Scheveneels W et al (2004) Effects of vascular endothelial growth factor (VEGF) on motor neuron degeneration. Neurobiol Dis 17:21-28

74. Warren L, Manos PD, Ahfeldt T, Loh YH, Li H, Lau F et al (2010) Highly efficient reprogramming to pluripotency and directed differentiation of human cells with synthetic modified mRNA. Cell Stem Cell 7:618-630. https://doi.org/10.1016/j.stem.2010.08.012

75. Winkler DD, Schuermann JP, Cao X, Holloway SP, Borchelt DR, Carroll MC et al (2009) Structural and biophysical properties of the pathogenic SOD1 variant H46R/H48Q. Biochemistry 48:34363447. https://doi.org/10.1021/bi8021735 
76. Zetterström P, Andersen PM, Brännström T, Marklund SL (2011) Misfolded superoxide dismutase-1 in CSF from amyotrophic lateral sclerosis patients. J Neurochem 117:91-99. https://doi.org/10.111 1/j.1471-4159.2011.07177.x

77. Zetterström P, Graffmo KS, Andersen PM, Brännström T, Marklund SL (2013) Composition of soluble misfolded superoxide dismutase-1 in murine models of amyotrophic lateral sclerosis. Neuromolecular Med 15:147-158. https://doi.org/10.1007/s1201 7-012-8204-Z

78. Zetterstrom P, Stewart HG, Bergemalm D, Jonsson PA, Graffmo KS, Andersen PM et al (2007) Soluble misfolded subfractions of mutant superoxide dismutase-1s are enriched in spinal cords throughout life in murine ALS models. Proc Natl Acad Sci USA 104:14157-14162. https://doi.org/10.1073/pnas.0700477104

Publisher's Note Springer Nature remains neutral with regard to jurisdictional claims in published maps and institutional affiliations. 